\title{
Imagining Law:
}

Curated Narratives of Sexual Assault in The Ghomeshi Effect

$$
\text { by }
$$

$$
\text { Sydney Jacklin }
$$

A thesis submitted to the Faculty of Graduate and Postdoctoral Affairs in partial fulfillment of the requirements for the degree of

\author{
Master \\ of Arts \\ in
}

Legal Studies

Carleton University

Ottawa, Ontario

(C) 2017

Sydney Jacklin 


\begin{abstract}
$\underline{\text { Abstract }}$
This project explores how myths of law are aesthetically animated. I unpack narratives of sexual violence, trauma, and social transformation presented in the verbatim theatre performance of The Ghomeshi Effect. I suggest that while the producers of the play claim that the verbatim methods authentically tell experiences of sexual violence, their representation of these narratives reproduce broader myths of law as an ordered system of truth. Stories of sexual violence in this performance are not authentic representations, but an aesthetic platform through which the power of law is animated.
\end{abstract}




\section{Acknowledgements}

Special thank you to Professor Stacy Douglas for challenging me and pushing me to my limits. Your teaching is insightful and your work is inspiring.

Thank you to my second reader, Professor Ummni Khan for dedicating so much time and patience helping me evolve this project.

Thank you to Michelle and Cheryl for editing way too many drafts.

To my closest friend, Jake. Thank you for providing me with a soundboard for ideas and those much-needed glasses of wine and cups of coffee. I am forever grateful for your companionship.

To my partner, Josh. Thank you for your support, care, and kindness. You have taught me how to approach life thoughtfully and patiently.

Finally, thank you to my mom, dad, and brother for constantly inspiring me to be creative and to do what I love. 


\section{$\underline{\text { Table of Contents }}$}

\begin{tabular}{lr} 
Abstract & i \\
Acknowledgements & ii \\
Table of Contents & iii \\
Introduction & 1 \\
The Jian Ghomeshi trial & 6 \\
Chapter breakdown & 11 \\
Methodology & 14 \\
Conclusion & 17 \\
Locating aesthetic interruptions of law & 19 \\
Introduction & 19 \\
Curating myths in verbatim theatre & 21 \\
Curating myths in law & 27 \\
The aesthetics of law & 35 \\
Conclusion & 44 \\
Imagining law: Sexual assault, trauma, and social transformation in The Ghomeshi Effect & 47 \\
Introduction & 47 \\
Sexual assault and trauma & 51 \\
Social transformation & 59 \\
Law's purpose & 67 \\
Conclusion & 75 \\
Curating narratives: Law and community in The Ghomeshi Effect & 100 \\
Introduction & 103 \\
Truth claims & 106 \\
Turning points & 76 \\
Conclusion & 76 \\
Conclusion: Aesthetic interruptions & 79 \\
References & 88 \\
\hline
\end{tabular}


$\underline{\text { Introduction }}$

Catharsis brings transformation, even if it comes with sadness, recognition, tears, as well as memories one would prefer to forget. Even if outwardly, the play is not intended to be therapeutic but still, the subject matter is so personal and so intimately linked to many unmanageable feelings that it cannot help but become a means of liberation (Ruprecht, 2017). ${ }^{1}$

I grew up in theatre. For the last 30 years, my parents have managed a community theatre company in Perth, Ontario, and for as long as I can remember, theatre and the arts have been a part of my life. So, it is not surprising that my research has taken me full circle, intersecting the topics that have formed me personally and intellectually. ${ }^{2}$

I came to this project understanding the importance of both art and sexual assault support. For many years, I have worked and volunteered in the sexual assault peer support industry, while also having a keen interest in researching sexual violence and feminist approaches to victim advocacy. Considering my family history in theatre, I am no stranger to the performing arts, yet I always separated the two identities: my creative side and my advocate side. Until this project, I never considered how theatre and sexual assault advocacy intersect.

\footnotetext{
${ }^{1}$ This is an excerpt from The Ghomeshi Effect: Sexual assault results in something being broken! A cathartic encounter at the Gladstone Theatre, an article written by Alvina Ruprecht with Capital Critics' Circle (CCC). CCC is a theatre critic journal and website, focusing on reviewing professional and community theatre in the Ottawa area. CCC is affiliated with the Canadian Association of Theatre Critics and the International Association of Theatre Critics. Ruprecht is well known for her work with the Department of Theatre at the University of Ottawa and her 30 years spent as a reoccurring theatre critic on Ottawa Morning CBC.

${ }^{2}$ Coincidently, The Full Circle Theatre is the name of my parents' theatre in Perth. My parents first saw the building in the 1980s, shortly after they met, and considered buying it. In 2009, after three decades of establishing BarnDoor Productions, my parents bought what was then Charlie's Car Wash and transformed it into a performance venue. They came full circle, and continue to produce plays, musical performances, and film viewings in the space.
} 
My brother and I recently had a conversation about the power of theatre in communicating stories and experiences. ${ }^{3} \mathrm{He}$ is currently working on a verbatim theatre project with his theatre school graduates in which they ask questions about generational experiences with economic and social anxieties. To write the script, they have interviewed baby-boomers and millennials about their experiences with education, work, and financial security to pin-point any differences. Verbatim excerpts from the interviews are edited to create the script of the play. In my conversation with my brother about why verbatim theatre is necessary to communicate these stories of generational anxiety, he suggested that verbatim scripts maintain a level of authenticity that is lost in more conventional ways of writing stories and making up characters. As with any literary work, play, or novel, there is often a separation between fiction and non-fiction, signified by whether or not the source of the story came from something real or the imagination of the author. My brother noted that verbatim methods of script-writing take words and keep them intact in order to grasp an authentic representation. In a nutshell, for my brother, verbatim theatre methods make the story "more real" (S. Jacklin, Personal communication, October 18, 2017).

Theatre is not the only field that seeks authenticity. Between January and August 2016, I attended an 80-hour peer support training with a local rape crisis centre in Ottawa, Ontario. The centre's methods are non-medical and non-legal, meaning they recognize that institutions like medicine and law often produce more harm than solutions for victims of sexual violence. As with many rape crisis centres, they seek to provide an alternative method of response and support, one that values and empowers victims' experiences and decisions. Their mandate acknowledges that victims of sexual and domestic violence are

\footnotetext{
${ }^{3} \mathrm{He}$ is a new graduate from theatre school and is currently living the high-life of starving artists in Toronto.
} 
often not heard by medical and legal models in meaningful ways. Alternatively, peer support work, lead by community volunteers who are extensively trained in knowledge about the intersections of gendered and institutionalized violence are the basis of the Centre's outreach framework. Rather than a complaint or reporting process, rape crisis centres often focus on providing confidential spaces, like crisis lines, one-on-one support sessions, or peer-support focus groups. These centres work within principles of belief and active listening. ${ }^{4}$ During my training, the lessons consistently iterated that, unlike medical and legal models of reporting, rape crisis centres that focus on feminist, intersectional, and peer-support programming provide spaces for victims to authentically represent their own stories of violence and trauma. ${ }^{5}$ Peer support methods are seen to provide more meaningful support than law or medicine because of their perceived ability to authentically represent victims of sexual violence. Rape crisis centres that work with this model hold the perception that law often distorts experiences of sexual violence by placing them inside institutional influences that are considered to prioritize white-male experiences. Peer support models pose a contrast between rape crisis centres and law, specifically in their abilities to provide an authentic representation of sexual assault victim experiences, claiming that these centres can be a space outside of institutional biases.

The timing of my peer-support training overlapped with the high-profile case of Jian Ghomeshi, a Canadian radio personality who was accused of sexually assaulting several women he had worked with at the CBC. Naturally, he was the topic of discussion

\footnotetext{
${ }^{4}$ The principles of belief and active listening mean that when a service user comes to a centre or calls a crisis line, their stories and experiences with violence are to be acknowledged as truth and never judged. This is a main reason how rape crisis centres distance themselves from legal or medical models, noting that the centres do not take reports or spearhead investigations; they are meant to provide support and trauma counselling.

${ }^{5}$ Information gathered here about support work was gained during my peer support training sessions in Spring of 2016.
} 
IMAGINING LAW

in most of the training sessions at the Centre, as we talked about the impacts of institutional violence on victims of sexual assault and the limitations of legal responses. One woman who took the training with me, a local actor, director, playwright, and theatre critic, announced that she was starting a new theatre project. The project she described was a verbatim theatre show aiming to explore questions about sexual assault, the criminal justice system, and the impacts of law on victims of sexual violence. She stated that she wanted the project to give an accurate representation of victim experiences, both with sexual violence and trauma, as well as institutional responses to sexual assault. Like peer-support in rape crisis centres, she wanted the play to allow experiences of trauma and violence to be told authentically, without an institutional presence. At the time, she had only just begun and was in the process of sourcing people to interview, but she had already set a title: The Ghomeshi Effect (Ruano, 2016). My interest was piqued, and it was only a few months later, in January 2017, The Ghomeshi Effect opened at The Gladstone Theatre in Ottawa, Ontario.

Verbatim theatre and peer support have an interesting intersection: both are considered a more authentic and cathartic platform for storytelling that is outside the systemic contexts of law. In Ruprecht's (2017) review of The Ghomeshi Effect, she mentions the inevitable cathartic effect of the play, and that it has a transformative power, which can lead to a sense of liberation both for the authors of the stories and the audience of the show. She notes that it is the intimate and personal context of the stories told through The Ghomeshi Effect that have this liberating power. In this conversation of the play and in the support provided in rape crisis centres, there is the perception that their methods of storytelling and representation are distinct from law; where law fails to hear stories of 
sexual violence, leaving victims without resolve, the play finds a solution by representing individual stories of violence and trauma in a space that is percieved to be distinct from the institutional influences of law.

The perception of law and "outside" spaces of storytelling is not uncommon (Coughlin, 1995). Anne M. Coughlin (1995) talks about the use of autobiographical performances in "outsider" scholarship that reproduces the idea of the liberal individual. ${ }^{6}$ Coughlin (1995) argues that while autobiographical storytelling of outsider experiences is considered to create radical, transformative and subjective ideas external to a universal law, this form of representation is not free from cultural bias. She notes, radical storytelling is perceived to liberate "outsiders to author a more authentic account of their experiences than traditional legal discourse permits", however these stories are not unoccupied by culture (Coughlin, 1995, p. 1238). Coughlin (1995) goes on to argue that by failing to acknowledge the cultural influences imbedded in "radical" storytelling, this scholarship produces conditions, such as unquestioned universal truths, stock performances like 'the victim', and the promise of a "new collectivity" that shares a vision of a better future (Coughlin, 1995, p. 1250). Although autobiographies are perceived to inspire more subjective, and therefore authentic accounts of experiences, Coughlin (1995) argues that they too are imbedded in liberal culture and are not as different from law as is assumed. Coughlin's (1995) argument shows that spaces we perceive as the 'outside' are still influenced by cultural myths.

This thesis takes up similar questions to that of Coughlin's (1995) project. I agree with Coughlin's argument, that autobiographies or personal stories are not separated from

\footnotetext{
${ }^{6}$ In Coughlin's $(1995,1229)$ article, she defines the "outsider" as the voices of queer, feminist, critical race, and gay scholars that are often not heard in law. She also mentions that the term "outsiders" has come to signify "diverse members of the community" that are not included in law's focus on the white-male universal subject (Coughlin, 1995, 1230).
} 
IMAGINING LAW

the cultural framework in which they exist. Yet, while Coughlin focuses on the ways in which liberal culture is manifested through the construction of the subject in autobiographical storytelling, I consider how myths of law as an ordered system of truth are produced through the separation of legal and theatrical representations of sexual violence. In particular, I find that The Ghomeshi Effect's overstated differences between art and law produce a narrative of law as an ordered and coherent system of truth. When talking with my brother about verbatim theatre, he made an interesting point: although the words from the interviews are kept intact, the playwrights still edit and organize them to make them more meaningful for the purposes of the play. Even if words are kept intact, whether in a rape crisis centre or in a verbatim script, is it ever possible to grasp an authentic representation? Are the gaps between law and art as far as they are imagined? This thesis will explore these questions and argue that the gaps between law and art are not as far as they seem.

\section{The Jian Ghomeshi trial}

On March $24^{\text {th }}, 2016$, Jian Ghomeshi was acquitted of four counts of sexual assault and one count of choking to overcome resistance (Young, 2016). The sexual assault charges against the former $\mathrm{CBC}$ radio host and Canadian radio icon were front and centre in the news and social media for almost two years. Called "Ghomeshi Gate", the scandal first made its appearance in October 2014 when CBC officially announced its separation from Ghomeshi (Wynne-Jones, 2014). The reasoning behind Ghomeshi’s firing alluded to sexual harassment and assault allegations, citing a blog post published on the style and fashion blog, XOJane. The blog post explains Carla Ciccone's experience with sexual harassment. The post entitled, "It happened to me: I accidentally went on a date with a 
IMAGINING LAW

presumed-gay Canadian c-list celeb who creepily proved he isn't gay" told the story of meeting "Keith", a well-known radio show host in Canada who was loved for "his views, interviews and radio voice" (Ciccone, 2013). Ciccone describes her uncomfortable date with Keith and how the culminating moment of the evening was when he touched and grabbed her without her consent. After Ciccone's post was published, four women anonymously came forward with stories of sexual assault and harassment in the work place by their coworker, Jian Ghomeshi. All four women made citations to Ciccone's post, stating that "Keith" was, in fact, Ghomeshi.

The allegations were not limited to those four women who came forward. The four anonymous women that shared their stories were the first in a total of 23 allegations of sexual assault against Ghomeshi (MacMullin, 2014). Most remained anonymous, with six using their real names (including Lucy DeCoutere, known for her role of Lucy in Trailer Park Boys). Three of the 23 allegations were brought to trial. Jesse Brown from Canadaland, an independent podcast and radio programming network, and Kevin Donovan from The Toronto Star broke the story of the allegations against Ghomeshi with an article investigating the women who came forward. The article notes that Ghomeshi had "struck them with a closed fist or open hand; bit them; choked them until they almost passed out; covered their nose and mouth so they had difficulty breathing; and that they were verbally abused during and after sex" (Donovan \& Brown, 2014). One woman even noted that, while at work at the CBC Ghomeshi had told her: "I want to hate fuck you" (Donovan \& Brown, 2014). After his dismissal from the CBC, Ghomeshi turned to Facebook to write a public response to the allegations of sexual assault, stating that none were true, that all actions had happened with their full consent, and that he had become the target of 
"harassment, vengeance and demonization" (Donovan \& Brown, 2014). Ghomeshi wrote that the women coming forward were part of a smear campaign to end his career. He wrote, 'I've been fired from the CBC because of the risk my private sex life being made public as a result of a campaign of false allegations pursued by a jilted ex-girlfriend and a freelance writer" (Ghomeshi, Facebook, 2014). The post continues to describe Ghomeshi's BDSM sex practices, which he alleges always involve lengthy discussions of consent and boundaries between him and his partners.

The coverage of Ghomeshi's trial was extensive. Daily reports narrated the details of the trial and live Twitter feeds gave play-by-plays, describing the expressions and feelings in the court room (CBC, 2016; Globe and Mail, 2016; The Toronto Star, 2016). The coverage produced a tremendous amount of public interest. Throughout the unfolding of the events that led up to Ghomeshi's acquittal, there was a massive response on social media to the allegations and charges. Multiple factions arose in this response. Some aligned with Ghomeshi and fought for his acquittal, others held strongly that due process and legal proceedings were the only method for proving his innocence or guilt (MacDonald, 2016). There was also an overwhelmingly strong response from feminist movements against sexual violence, which argued that questioning the credibility of the complainants and the other women who came forward was an unjust practice of criminal law and proof that the legal system is broken (CBC, 2016; Karolyn Coorsh, 2016). In this outpouring, many stated that the trial had a significant impact on the conversation of sexual violence, but as well on discussing the role of community as a support network and space of justice for victims.

News media began labelling the growing conversation of sexual assault "the Ghomeshi effect” (Boesveld, 2014; Kingston, 2014; Kirsch, 2016; Ryan \& Robinson, 
2016). This response, an overwhelming support for the complainants' of the Ghomeshi trial, used the hashstags \#IBelieveLucy and \#BelieveSurvivors to mobilize the movement across social and news media. The movement emphasized that current court proceedings and legal tactics were unsuitable for hearing experiences of sexual assault, and that major legal reforms needed to be introduced (The Canadian Press, 2016). Discussions coming out of the \#BelieveSurvivors movement focused on illuminating legal processes, such as cross-examinations, that question witness credibility, with the intent of shifting the focus in conversations about sexual violence away from victims and witnesses and toward the limitations of the criminal justice system (Hasham, 2016; Loriggio, 2016). What solidified the feminist movement's position that the legal system was broken was Ghomeshi's acquittal. In his decision, Justice William B. Horkins reasoned that the complainant's faulty memories and persistent contact with Ghomeshi after the events made his guilt and their trust questionable. He stated:

However, one of the challenges for the prosecution in this case is that the allegations against Mr. Ghomeshi are supported by nothing in addition to the complainant's word. There is no other evidence to look to determine the truth. There is no tangible evidence. There is no DNA. There is no "smoking gun". There is only the sworn evidence of each complainant, standing on its own, to be measured against a very exacting standard of proof. This highlights the importance of the assessment of the credibility and the reliability and the overall quality, of that evidence. At trial, each complainant recounted their experience with Mr. Ghomeshi and was then subjected to extensive and revealing cross-examination. The cross-examination dramatically demonstrated that each complainant was less than full, frank, and forthcoming in the 
information they provided to the media, to the police, to crown counsel and to this

Court (ONCJ 155, 131-132, p. 23, 2016).

Feminist critiques of the decision argue that the judge's finding of not guilty suggested that complaints of sexual assault are often deceitful. The critiques argued that the law failed to hear and understand the impacts of trauma on the three complainants, perpetuated myths about rape and gender, and closed the doors to victim justice. This critique sparked discussions about an alternative to the broken legal system.

While many of these discussions occurred through social and news media, different tactics of reacting to the trial included protests and artistic expressions. Throughout the trial, protests and rallies erupted outside Old City Hall in Toronto, Ontario (Coorsh, 2016). Signs of the protest echoed the commonly cited hashtags and exclaimed frustration with processes of cross-examination and witness testimony. Well after the verdict was given, responses to the trial persisted. New responses took form in artistic ways of engaging with the trial and subject matter, including the verbatim dance-theatre performance, The Ghomeshi Effect (Ruano, 2016). ${ }^{7}$

The play was formed by curating verbatim experts from 40 interviews with sexual assault victims and legal experts and setting the text to choreography and dance. The play is meant to be a commentary on conversations of sexual violence and law. Descriptions of

\footnotetext{
${ }^{7}$ There was another artistic response to the Ghomeshi trial that made headlines. A "rap symphony" created by Jordan O'Connor and Bobby McIntosh in Toronto, Ontario. Performed on the one-year anniversary of the Ghomeshi verdict, the rap symphony creators wanted the piece to raise "questions about consent and intent" by setting up conversations about experiences with sexual violence in relation to the Ghomeshi verdict (Gillis, 2017). The rap symphony incorporates recorded voices of six women reacting to excerpts from the Ghomeshi verdict and telling their own experiences with sexual violence. While the rap symphony also speaks to narratives of law, I chose to analyze The Ghomeshi Effect because it offers more opportunities for observation and data collection, mainly due to its local proximity to my place of study. That being said, a limitation to this project may be that my analysis takes into account only one artistic expression of sexual violence and law, though I caveat by noting that my analysis of The Ghomeshi Effect is meant only to understand how this particular art piece engages with the subject matter.
} 
IMAGINING LAW

The Ghomeshi Effect suggest that their responses to the trial provide space for conversation about sexual assault in ways that law cannot. In this claim, law cannot represent victims and provide justice when needed. Rather, the claims suggest that art, like the performance of The Ghomeshi Effect, must step in as an outside voice and fill in where law has failed.

This thesis focuses on how law is imagined in The Ghomeshi Effect. The play's engagement with performance, dance, and theatre intersect with narratives of sexual violence, trauma, justice, social transformation, and law. Their main claim places a separation between art and law, arguing that law produces ideals of sexual assault and trauma by curating victim's realities with trauma and silencing their stories of violence. As an alternative to law, critics and producers of the play assert that The Ghomeshi Effect's engagement with stories of violence is more authentic and able to grasp the nuances of trauma more meaningfully. This is specifically justified with claims that their verbatim script "gives a voice" to victims of sexual assault by maintaining their original dialogue and reflecting the emotional weight of trauma through dance and theatrical staging (The Ghomeshi Effect, 2016). To this end, The Ghomeshi Effect is considered more than just a play. It is considered a therapeutic and cathartic experience that enables pathways to justice, healing, and social transformation for victims of sexual violence in ways that law cannot.

\section{Chapter breakdown}

Focusing on theories of law as discussed by Costas Douzinas and Adam Geary, I understand how law can manifest as an aesthetic phenomenon. By aesthetics, I mean the ways in which something is imagined and created, specifically through image and narrative. By turning to Douzinas (1999) and Geary (2001), I situate how law is imagined 
IMAGINING LAW

and produced, appearing aesthetically in imaginations and creative projects. In this sense, law is not necessarily any one thing or way of understanding, but is produced through the ways we think, speak, write, and perform it. In particular, Douzinas (1999) and Geary (2001) note that law is ideologically produced through image and narrative as a system of truth, which constitutes how we know ourselves through the notion of rights and freedoms. Douzinas (1999) and Geary (2001) outline how law is imagined as transcendent and universal, that is distinct from the world of the social and beyond common interactions between people. Rather, in Douzinas (1999) and Geary's (2001) understanding of law's aesthetic, narrative, image, and other creative ways we use to represent our imaginations make law into something that is ordered, objective, and rational. Drawing on Roland Barthes, I suggest that representations of law are part of a myth-making process that reconstitute law's power and place, specifically through conversations of sexual violence.

Chapter One looks into the ways law appears aesthetically and why this may be a problem for feminist discussions of sexual violence. First, I outline how image and narrative are able to produce knowledge about everyday realities. Looking to Barthes (1957; 1980; 1984), Irving Goffman (1947), and Umberto Eco (1977), I emphasize that representation through image and narrative is tied to a process of myth-making. Next, I outline prevalent feminist legal literature on sexual assault to situate how feminist conversations have imagined law in relation to sexual violence. I primarily look at the work of Carol Smart (1989) to argue that feminist conversations have not gone far enough to challenge how sexual assault is talked about in the framework of law. Rather, I suggest that this specific scholarship has imagined a form to law's power in constituting myths of sexual violence and trauma. The last section of Chapter One suggests my solution: introducing 
IMAGINING LAW

legal aesthetics into feminist conversations of sexual violence. Outlining Douzinas (1999) and Geary's (2001) understanding of legal aesthetics, I argue that conversations of sexual violence should recognize law as a system of representation that appears in aesthetic ways. When law is not acknowledged as such, we lose sight of subtler and passive ways the feminist movement reproduces the aesthetic power of law and maintains myths about sexual violence and trauma.

Chapter Two analyzes the script of The Ghomeshi Effect in order to draw out the narratives of sexual assault, trauma, and social transformation in the play. My analysis of the script points to how these narratives imagine an ideal order of law and truth by identifying the failures, and therefore the purposes of law. Furthermore, I show how law appears aesthetically in these narratives arguing that the play's representation of sexual violence inadvertently perpetuates the myth that law's purpose is to reflect values of the community and maintain an order of truth-telling and accountability.

The play presents law by arguing that law's purpose is to protect collective values and provide justice to victims of sexual assault. However, the play suggests that law fails to fulfill its purpose and leaves victims unheard and misrepresented. The Ghomeshi Effect's solution is social transformation, specifically in the form of community accountability and legal reform. The narratives of sexual assault, trauma and social transformation in the play does not imagine a new legal order, but desires a return to one that is assumingly fixed and whole, and is able to uphold its purpose of reflecting collective values.

The last chapter analyzes primary interviews with the director and choreographer of The Ghomeshi Effect speaking on how they approached the creation of the play and the impacts they have seen. This chapter argues that the narratives drawn out in Chapter Two 
IMAGINING LAW

are not just based on my interpretations, but are influenced by the producers. However, Ruano and Griffin separate themselves from the creation process, arguing that the verbatim theatre style allows the play to be an authentic representation of victim's stories and can be a space for victims to be heard when law fails them. Separating themselves from law, the producers of The Ghomeshi Effect imagine the play and the community formed by it to be an alternative to a failing legal system. They maintain that where law fails to protect collective values and provide justice for victims of sexual assault, the play and its surrounding community fills the gaps of law until meaningful social transformation is established through legal reform. Underlying imaginations of law's purpose produced through their narratives of sexual violence, trauma, and social transformation are left unquestioned. In The Ghomeshi Effect, law is imagined and presented as something: a rational and ordered system of truth. However, I suggest that imagining law in this way reproduces law's power and place in conversations of sexual violence.

\section{Methodology}

The data for Chapter Two was gathered by analyzing themes presented in the text of the script for The Ghomeshi Effect. I primarily focus on the themes of sexual assault, trauma, and social transformation. Drawing on all three themes, I gather an idea of how the play narrates law in the context of sexual violence. It is important to acknowledge that the script is only a partial representation of the play in its entirety. Eli Rozik (2008) notes that the script of a play is only a partial step in producing meaning. The performances and staging themselves have significant impact on the effect the discourse has on the audience (Rozik, 2008). Theatre performance analysis scholars insist that analyzing a play should focus on the interaction between the audience and the performance, stating that it is through 
IMAGINING LAW

this relationship that meaning is produced (Rozik, 2008). However, this idea of performance analysis emphasizes that meaning is most impactful at the point of interpretation. My analysis of The Ghomeshi Effect approaches performance analysis differently. I seek to highlight that the authors and producers of the play have an influence on meaning, even before audience interpretation is involved. This is why I chose to contextualize my analysis in relation to the text of the play, so as to demonstrate how the script was organized and edited to produce a set of desired themes. The editor and director of the play, Jessica Ruano, generously gave me access to the script for the purposes of my analysis.

The theatrical setting of the performance is still important. Patrice Pavis (1998, p. 106) argues that the discourse of a play is connected to its mise en scène and is, "in relation to its conditions of production, which are determined by the particular use made by the 'authors' and the various artistic systems available to them at a given historical time". ${ }^{8}$ In other words, the staging of the play is an important aspect of meaning-making and can change an interpretation of a text. The text is known by the way it is presented and framed in the creative setting of the play. During my data collection, I saw the play twice. I took notes of the performances that included details about the choreography, sets, props, costumes, lighting, and sound. Both times I saw the play, the houses were sold out, and the audiences averaged ages of 20-40 years old. The auditorium itself was an intimate blackbox theatre with raked seats that sat about 150 people. The set was minimalistic; the only set pieces were six metal desks. The rest of the play's setting relied on lighting, sound design, and the movement of the actors. As I watched, it became clear that my

\footnotetext{
${ }^{8}$ A term in theatre to describe the arrangement of the properties (objects, settings, scenery, movement) of a scene, also known as staging (Pavice, 2008).
} 
IMAGINING LAW

interpretations of the play were inconsistent. Especially as I entered my second viewing (a week after the first), I noticed that I held different assumptions and expectations (in part due to the fact that I had already read the script several times and that I had gone to the performances with different groups of people). If I was to depend on a performance analysis based on my interpretation of the play alone, I would not grasp an understanding of the play that I was seeking out; particularly the ways authorial intent impacts the presentation of verbatim stories of sexual assault.

Rather than interpreting the performance as an audience member, I instead gathered information about the producer's intentions when editing, staging, and choreographing the play. The data for Chapter Three was gathered from coding primary interviews with the play's director, Ruano, and lead choreographer, Amelia Griffin (Babbie \& Benaquisto, 2010). I asked both Ruano and Griffin similar questions, but curated these questions to focus on their particular expertise in the production of The Ghomeshi Effect. Questions for Ruano focused on the editing and staging of the play, whereas questions for Griffin primarily focused on the creative choices in choreography, though there was some overlap. The interviews were initially audio recorded, but were then transcribed into a text document. I coded the text of the interviews using the same themes I drew out of the script: sexual assault, trauma, and social transformation in order to connect the authorial process to my interpretation of the script. All interviews were given with permission from the Carleton University Research Ethics Board. 
IMAGINING LAW

\section{Conclusion}

Since the Ghomeshi trial ended, there have been many more allegations of sexual assault against men in power that have sparked similar feminist-based conversations. At the time of the Ghomeshi trial, allegations against Bill Cosby had also just surfaced. Most recently, Donald Trump and Harvey Weinstein (co-founder of Miramax and former movie producer) also face allegations of sexual assault. In both cases, much like in the Ghomeshi trial, the allegations were followed with a rise of Twitter hastags, like \#NotOkay and \#MeToo, to highlight the pervasiveness of sexual violence and the silence faced by victims of sexual assault (Khomami, 2017). Shortly after the Weinstein exposé, two allegations of sexual assault were made against Canadians Eric Salvail (well-known Quebec radio host) and Gilbert Rozon (founder of Just For Laughs), both appearing over social media. The hashtags continue to be used by millions of Facebook and Twitter users to tell their experiences with sexual assault attempting to interrupt legal responses (Khomami, 2017). By looking at the prevalence of the recent \#MeToo and \#NotOkay movements, it is clear that experiences with sexual assault are not uncommon. The feminist work in supporting victims of sexual, domestic, and gendered violence has tremendous value. Rape crisis centres are often overwhelmed with calls and visits from people needing support and advocacy, so much so that the limited resources and labour available is not enough to help them. Artistic projects, like theatre, have a potential to open more avenues for support when rape crisis centres are not enough to meet demand.

Although this project argues that the differences between art and law are not as strict as they may seem, this does not mean that I am arguing that they are the same. We can trace the similarities between art and law in their dependence on representation and in 
the ways law appears aesthetically. However, art is a different form of representation than law. This project does not intend to be prescriptive of art. In other words, I do not wish to suggest that art has a singular purpose. My main concern with The Ghomeshi Effect is not their use of verbatim theatre methods or the subject matter they wish to represent. Rather, I take concern with their dedication to a project of truth-telling. Creative spaces like theatre can play with genre, dialogue, and visual representation without the pretext of needing to tell the truth. Coughlin (1995) notes that a constraint of autobiography is its commitment to truth-telling and finding a conclusion to its narrative. She continues to argue that this commitment is the very thing that reproduces the legal form: the necessity for truth and a rational conclusion. Art does not necessarily have a presumed need to uphold this commitment. Narratives told through theatre do not have to be perceived as truth and can be left without resolve. Art has the capacity to play with the expectations of a narrative. Representing topics like sexual violence can happen in a variety of different ways and can mean more space for aesthetic interruptions of law. In this sense, these narratives have the potential to illuminate the many ways law can be imagined and represented. Artistic approaches of interruption mean developing a more thoughtful approach to discussions of law, one that acknowledges how law is produced aesthetically through narratives and the imagination. 
IMAGINING LAW

\section{Locating aesthetic interruptions of law}

\section{Introduction}

A post on The Ghomeshi Effect's blog entitled, Courage: Debunking Myths and Opening a Dialogue About Sexual Violence outlines the impossibility of knowing someone's trauma and pain and notes that these experiences are ultimately invisible (Psimenatos, 2016). ${ }^{9}$ However, because of this invisibility, the author argues that victims of sexual assault are faced with tremendous difficulties when reporting instances of sexual violence to police. The author of the post states that "the judicial system, as it is right now, is ill-equipped to hear cases of this nature" (Psimenatos, 2016). Her solution to the dangers of an ill-equipped judicial system is to find alternative narratives of sexual violence through art. The author of the post ends with this message:

The Ghomeshi Effect is groundbreaking for broaching the subject of sexual violence because the director gives survivors a voice by using their own words about their experiences, and in doing so, supports truth and counters the culture of silencing people who have experienced sexual violence [sic]. It is the responsibility of all people - women, men, parents, community leaders, lawmakers and government to create a society in which sexual violence is recognized as a serious crime, punished accordingly and prevented through education about consent. Hopefully, the play will not only make people aware of sexual violence, but it will give them courage to spark a discussion around what constitutes sexual violence and how citizens and communities can work together to combat this crime. (Psimenatos, 2016)

\footnotetext{
${ }^{9}$ The piece was a community post by an author external to the process of producing The Ghomeshi Effect.
} 
The author (2016) marks a difference between the judicial system and art in their abilities to narrate experiences of sexual violence and trauma. She emphasizes that the truth of victims' stories can be communicated through art, but not through law.

How wide, then, is the gap between law and art? This chapter argues that the differences between law and art which the author of the blog post renders in her discussion about The Ghomeshi Effect are overstated when speaking about resistance to sexual violence. These differences are particularly problematic when artistic narratives of violence and trauma are considered to be authentic representations of victim realities.

Rather than thinking of art and law as separate, it may be useful for resistance movements, like the feminist movement against sexual violence, to understand that there is an aesthetic engagement present in both law and art. Connected through their use of image and narrative, art and law practice similar methods of curating experiences. Law and art can be considered as different frames for investigating sexual violence. However, despite differences in how experiences are presented, narratives of sexual violence depicted through law and art are both curations. Narratives of sexual violence and trauma that are read within the scope of law and art are representations that "[create] a life and meaning of [their] own as it goes along" (White, 1973, p. 862). In this sense, staking the claim that narratives of sexual violence presented through art are more truthful than those in law produces an unnecessary duality between both frameworks.

In the first section of this chapter, I argue that representations in images, literature, and performance are not a reflection of truth. Turning to an analysis of verbatim theatre methodologies, I suggest that claiming verbatim scripts as an authentic representation of an event reinforces myths of cultural ideals, particularly of law. In the second section of 
IMAGINING LAW

this chapter, I outline key feminist scholarship, which argues that law's power is reinforced through the silencing of sexual assault victims. I consider how law curates experiences of violence through testimony, memory, and time and produces myths about gender and sexual assault. In doing so, I suggest that law's power is not only reproduced through the silencing of sexual assault victims, but also through these feminist narratives that imagine law as having this power. Finally, the third section of this chapter outlines law's aesthetic. I argue that law, like art, is a system of representation and its power survives through aesthetic means, like image, narrative, and the imagination. I suggest that law's power is particularly present in narratives about social transformation that argue for individual rights and collective moralities as 'cures' for harms done. I suggest that feminist scholarship, which speaks to sexual violence and sexual liberation, reproduce the myth that law is something: "a knowable, meaningful category that is" (Douglas, 2015, p. 147) Instead, I propose that aesthetic interruptions should highlight the ways law becomes something ordered and knowable by being represented through narrative and image.

\section{Curating myths in verbatim theatre}

In The Death of the Author, Roland Barthes (1984) argues that the text is all that exists in literary works. He argues that attempts to explain a text by relating it to the author produces a limit to the text and "closes" its writing (Barthes, 1984). By stating the author is dead, he suggests that the power of a text is located in interpretation, not in its writer: "a text's unity lies not in its origins but in its destination" (Barthes, 1984, p. 148). In staking this claim, Barthes (1984) imagines that the text is not linked to intent or history, but a reader's interpretation. 
IMAGINING LAW

Barthes (1980) has a similar analysis of the image, specifically photography. In Camera Lucida, he speaks about the photograph as a tool of affect, a medium of representation that relies not on photography (as a method, tool, or aesthetic form) but the stickiness of a photograph's contents (Barthes, 1980). He notes that it is the "referent" of an image that "adheres" itself to a photograph - it is not the techniques or the histories of the form, but an affective quality of the image that defines its presence and its limits (Barthes, 1980, p. 6). He states:

Photography is unclassifiable because there is no reason to mark this and that of its occurrences; it aspires, perhaps, to become as crude, as certain, and noble as a sign, which would afford it access to the dignity of language...deprived of a principle of marking, photographs are signs which don't take, which turn, as milk does. Whatever it grants to vision and whatever its manner, a photograph is always invisible: it is not it that we see. (Barthes, 1980, p. 3)

A picture does not mark a particular point in history, in time, in space, or in memory. Rather, Barthes (1980) argues that photographs turn particular points into a referent. Lacking in completeness, the photograph fails to tell a whole history, but can grasp an affect - whether true to the moment or not. In this sense, the frame of a photograph is tied to its affective qualities that produce an interest in the meaning of a photograph and sustains it as a piece of art. ${ }^{10}$

\footnotetext{
${ }^{10}$ Barthes (1980) differentiates between two qualities of the photograph: The studium draws the spectator in to study and justify the photo, and the punctum, an affective hold a photo has on the spectator. Barthes (1980, p. 27-28) differentiates by noting "The studium is of the order of liking... the studium is inevitably to encounter the photographer's intentions, to enter into harmony with them, to approve or disapprove of them, but always to understand them", whereas "A photographs punctum is that accident which pricks me (but also bruises me, is poignant to me)".
} 
Using photography as an analytic, Barthes (1980) expands on his idea of mythologies by arguing that normative perceptions of everyday realities are produced and reproduced through interpretations of the photograph. In Mythologies, Barthes (1957) argues modern images and languages produce "myths" about everyday realities. He unpacks the connotations of cultural symbols and images to reveal the relationship between power and language and how myth normalizes particular cultural ideals (Barthes, 1957). Barthes (1980) suggests that interpretations of a photograph are reproductions of "cultural perceptions $[\ldots]$ whereby we become the makers and consumers of photographs carrying what one might call our pictorial mythologies" (States, 1987, p. 11). In this sense, interpretations of an image or text are not just subjective, but significant of the production and reproduction of myths about how we know the world.

Images and texts are significant frameworks through which we understand ourselves and the everyday. Works of art, like literature and photography, inspire a spectrum of interpretation. However, does Barthes's (1984) thesis in The Death of the Author necessarily apply to all artistic frames? This section explores various theories of representation and performance in cultural theory to define the importance of considering the framing and curation of a piece of art. Furthermore, I consider the impacts of ignoring authorial influence when reading and viewing a play written through verbatim methods.

Erving Goffman (1947) argues the frame of performance transforms an action into something playful. Goffman (1947) argues that transforming an action into play reduces that action into a series of patterns that signify what is happening (also known as keys). ${ }^{11}$

\footnotetext{
${ }^{11}$ In Goffman's (1947) frame analysis, keys are symbolic methods of performing social behaviours. For instance, Goffman (1947) cites an observation of otters by Gregory Bateson that notes the differences between real fighting and play fighting. Goffman (1947) argues that keys are the differential behaviours that
} 
Goffman (1947) links his theory of framing to the motivation of social behaviours in everyday realities. In frame analysis, Goffman (1947) notes that the frame is the context through which we understand the patterns of keys and the reason we are able to interpret them as signs with meaning. In the performance of a play, we understand the characters because of the set of keys that inform their importance and place in the narrative.

This process of understanding can be linked to the production of myths. Umberto Eco (1977) speaks about framing using the concept of ostentation, which is the process of performing and assigning meaning to a representation. Eco (1977) notes that signs in theatre are different than signs in an image. He argues that performance in theatre does not necessarily produce signs, as an image or word may (Eco, 1977). Rather, Eco (1977) states that a sign in performance "has been picked up, among the existing physical bodies and it has been shown or ostended". Eco (1977, p. 110) notes that ostentation is a process of generalizing, or "de-realizing" an object or action to associate it with an entire group or class. ${ }^{12}$ The process of ostentation involves an underlying message. Eco (1977), referring to the underlying message as a "metalinguistic message" or "ideological abstraction", notes that ostentation relies on a particular set of tropes or ideals that adhere to forms of socialized knowledge. Ostenation can be understood in relation to Barthes's myths as cultural ideals become normalized in our imaginations.

\footnotetext{
"transform" a real fight into play. He states the key is "the set of conventions by which a given activity, one already meaningful in terms of some primary framework, is transformed into something patterned [...] The process of transcription can be called keying" (Goffman, 1947, p. 43-44).

${ }^{12}$ Eco (1977) uses the example of a drunk man characterized on stage. He states that as the drunk man is presented in the scene, he is not the real body of the drunk man but a representation: "he has become a semiotic device; he is not a sign" (Eco, 1977, p. 110). Eco (1977) notes that details of his physical presence, like his rosy cheeks, ruffled facial hair, and worn-out clothing are characteristics that transform him into the drunk man. Eco (1977) notes that these characteristics are references to how we imagine the drunk man, but are still an abstraction from the real thing.
} 
Performance in theatre produces (and reproduces) signs and ideals. Eco's (1977) suggestion that ostentation 'pulls from' already existing characteristics distances the performance and suggests that theatre, as art, exists outside the systems that produce the ideals in the first place. Theatre is merely 'playing'. However, Goffman's (1947) idea of framing and Eco's (1977) idea of ostentation is a process of representing cultural norms through performance. If we consider Barthes's concept of myth, performance is one way through which cultural ideologies are presented as obvious and normal.

For Barthes (1957), the process of myth-making is dependent on interpretations. However, when reading and viewing verbatim theatre, there is more at play. Traditions of verbatim theatre not only involve a continuous reference back to the origin of the text (the original interviews), but also involve a process of curating the interviews. Verbatim theatre, though understood as a process of documenting and archiving a historical event, is not a reproduction of the truth of the event (Derbyshire \& Hodson, 2008). Rather, verbatim theatre is a curated representation. Claims that insist verbatim theatre authentically reproduce experiences further the normalization of myths produced through the theatrical framework.

Verbatim theatre began in Britain in the 1990s (Derbysire \& Hodson, 2008). Understood as a way of documenting witness accounts and experiences, verbatim theatre is a tactic of political art and public story telling (Derbyshire \& Hodson, 2008). Most famously, verbatim theatre reproduces major historical events in an attempt to communicate other narrations of the story. ${ }^{13}$ Verbatim theatre attempts to use real stories

\footnotetext{
${ }^{13}$ London's Tricycle Theatre performed a series of verbatim pieces dedicated to interrupting human rights tribunal processes (Derbyshire \& Hodson, 2008). Half the Picture (1994) Nuremburg (1996), Srebrenica (1996), The Colour of Justice (1999), to name a few, use public records of legal hearings to tell an alternative story to the way the trials are told in history (Derbyshire \& Hodson, 2008). Other kinds of verbatim theatre,
} 
from real people to communicate and comment on political and legal injustices. The effect of this is meant to produce these stories in a "dramatic context" (Derbyshire \& Hodson, 2008, p. 199). To this end, audiences of verbatim theatre are expected to respond, "on an imaginative rather than practical level" (Derbyshire \& Hodson, 2008, p. 199). In this description of verbatim theatre, there is a separation made between representations in theatre and representations in explicit political, legal, or historical fields. Verbatim theatre is often described as a more emotional and authentic investigation of political events, rather than, for instance legal engagements. ${ }^{14}$ As displayed in Psimenatos's (2016) claim that opened this chapter, verbatim theatre is recognized as a way to give a voice to victims when political and legal avenues deny their stories. Situating verbatim theatre as authentic assumes that hearing real stories told by real people is synonymous with hearing the truth.

Despite using verbatim quotes from interviews of people speaking authentically, putting together a verbatim script and staging it requires curation and intent. For instance, there are choices made about how to present the lines through the narrative of the play. Blocking, choreography, costume and set design all play vital roles in framing how the interviews are presented. These variables change and evolve the meaning of the original interviews. Although these changes are not necessarily harmful, claiming that these theatrical representations of an event are authentic reproduce myths about everyday life by framing them as truths.

like The Ghomeshi Effect, uses personal testimony outside of law to discuss experiences with law and violence (Ruano, 2016).

${ }^{14}$ Derbyshire \& Hodson (2008, p. 201) note that verbatim theatre "provides an audience with a particular and distinct kind of theatrical experience". In their article, they discuss three verbatim pieces performed by Tricycle Theatre: Guantanamo: Honor Bound to Defend Freedom (2004), My Name is Rachel Corrie (2006), and Called to Account (2007). Each piece interrogates legal hearings and testimony. Derbyshire \& Hodson (2008, p. 201) note that the pieces present authentic displays of the events and are intended "to inform, to inspire compassion and to raise consciousness". 


\section{Curating myths in law}

Since the 1980s, feminist scholarship has discussed how law narrates experiences of sexual violence. This is a particular concern of many post-structural feminist scholars who explore how knowledge is produced and normalized, specifically how legal knowledge overshadows other forms of knowledge such as that found through feminist thought. Foundational feminist legal thinkers, like Carol Smart (1989), argue that judicial processes construct and normalize myths about rape and trauma. I argue that Smart's (1989) analysis of law simultaneously constructs law as having a knowable order of malecentred dominance. This section explores the ways feminist legal thought understands how narratives of sexual violence are framed through law. In particular, I focus on feminist scholarship that analyzes the framing effects of legal testimony and sexual assault case law in producing presumptions of violence and trauma. This body of work argues that law produces a narrative of sexual assault that is inauthentic to experiences of trauma and sexual violence. Their analysis claims that what is represented is not the victims of sexual violence, but law reinforcing its power through claims of truth. This feminist scholarship highlights how the power of law can be made present through legal narratives of sexual assault. However, by doing so, they also give a form and order to law through which it can be known.

In Feminism and the Power of Law, Smart (1989) analyzes how law's power extends beyond strict legal spaces. Using Michel Foucault's (1978) relation of truth and knowledge, Smart argues that law's power is the discursive production of knowledge about gender, sexuality, and violence. In a similar vein to Foucault's (1978) challenge of 
science's claim to truth, in which he notes that it is not necessarily truth that comes through scientific knowledge but a language that adheres to normative values of truth in society, Smart (1989) borrows this concept and places it onto the idea of law. ${ }^{15}$ She contends that the "lawyer's claim", much like a scientific claim, is idealized through a power/knowledge relation of truth (Smart, 1989, p.9). However, Smart (1989) notes that law does not call itself a science but rather establishes a regime of power through its own name. ${ }^{16} \mathrm{By}$ establishing distinct methodologies, processes, and languages, law becomes a discipline with expert knowledge that "sets itself apart from other discourses in the same way that science does" (Smart, 1989, p. 9). To this end, the name of law becomes much more than the authority of the court room, rather it is an allusion to a much grander regime of power, knowledge, and truth.

Smart (1989) argues that law's power is produced through law's claim to truth. Law's power is certainly present in the weight of a judgment of guilt or innocence, yet Smart (1989, p. 11) argues that it is more than just these "material effects" that reveal the power of law. She argues that the power of law makes other ways of understanding experiences ineligible in the framework of law. Smart (1989, p. 11) notes: "law exercises power $[\ldots]$ in its ability to disqualify other knowledges and experiences”. In relation to

\footnotetext{
${ }^{15}$ For Foucault (1978), power and knowledge are relational and hinge on a practice of 'telling the truth'. In History of Sexuality, Foucault (1978) argues that confessions are a regulated form of truth-telling through which knowledge about sexuality and identity is produced and justified. Power is made apparent through the regulation of these confessions, as social and institutional discourses manage which narratives of sexuality are considered 'normal'. In this sense, power/knowledge work simultaneously to produce and maintain cultural norms about identity. More importantly, Foucault (1978) did not consider this relationship to be totally damning. Rather, he argued that the relation of power/knowledge is both constraining as well as productive, meaning the perception of cultural norms can change as power/knowledge shifts. Smart (1989) applies the relation of power/knowledge to understand how legal discourses constitute knowledge of women's sexualities and experiences with violence.

${ }^{16}$ Law does not call itself a science, but legitimizes some knowledge through the use of science. Smart (1989) draws relation to the use of the 'psy' disciplines in producing legitimized knowledge on witness stands. Elizabeth Sheehy (2014) also speaks of this relation in her discussion of the battered women syndrome defense.
} 
IMAGINING LAW

producing narratives of sexual violence, the power of law transforms experiences of sexual assault into a narrative that fits the discursive framework of law. Legal framing does this by curating claims of sexual assault to satisfy gendered and sexed ideals of violence that validate (or not) victim experiences.

In Smart's (1989) analysis, legal narratives of sexual violence are not considered authentic representations of victim experiences because they are informed by malecentered ideals of femininity. In Smart's (1989) theory, law is part of a phallocentric culture that reinforces a script of normative gendered behaviour. Phallocentrism means that masculine sexualities and desires are centralized, overshadowing that of women and defining the very concept of womanhood. Smart (1989) argues that law has a particular framework of logic that justifies its gendered constructions as truth. She uses the idea of a "binary system of logic" to argue that law produces competing ideals existing in relation to one another (Smart, 1989, p. 33). ${ }^{17}$ For instance, man/woman, rapist/victim, consent/non-consent, or ideal victim/deviant woman. In Smart's (1989) analysis, law's framing of truth works through these binaries to legitimize (or not) harm. Smart (1989) argues that phallocentric gendered scripts reinforce ideas of the dangers of female sexuality and pleasure. In law, and in particular during the sexual assault trial, Smart (1989) argues that ideals of womanhood are defined as 'other-than man', simultaneously constituting the deviant woman. During the rape trial, Smart (1989) notes that it is the woman's behaviour that is at question as she is asked to explain, in pornographic detail, her account of the event. The "pornographic vignette", Smart (1989) argues, sexualizes the woman's body

\footnotetext{
${ }^{17}$ In her explanation of a binary system of logic, Smart (1989) acknowledges that the idea comes from French feminist writing. She uses it to specifically argue that binary ways of knowing cannot represent the ambiguities of rape (Smart, 1989).
} 
IMAGINING LAW

and holds her up against the image of the ideal woman. The image of the ideal woman is that of the pure, white, middle class mother (Smart, 1989). Smart (1989) argues that if the sexual assault complainant is able to satisfy this image, only then can she be known as the ideal victim and have her assault legitimized by law. Straying from this narrative of the ideal victim can result in law marking the complainant as deviant and questioning her experience of sexual assault (Smart, 1989). Smart (1989) argues that the ideal victim is made manifest in court as the rape trial displays "a process of disqualification (of women) and celebration (of phallocentrism) wherein her account of the event is displaced by normative gendered assumptions" (Smart, 1989, p. 35). In this explanation, law's phallocentric gendered script curates experiences of sexual assault through the malecentered constructions and produces the myth of the ideal victim.

Myths of gender and sex are not only located in law. Smart (1989, p. 12) uses the term "juridogenic" to describe law's encroachment into everyday realities. Smart (1989, p. 12) uses the term to speak to the "extending" of legal rights, like victim rights to privacy, as a "cure" for harms done. However, the juridogenic potential of law is not its cure, but its ability to cause greater harm, especially in cases of sexual assault as, she argues, victim experiences are curated to form narrow ideals of violence and trauma (Smart, 1989). These juridogenic properties of law are a way in which the power of law remains present. (Smart, 1989).

Smart (1989) acknowledges that the juridogenic force of law produces concerns for radical movements attempting to find spaces of resistance, namely in the very idea that law is stated as a force at all. She asserts that resisting law has two contradictory points: "One is the idea of law as a force for good (or bad), the other is the idea of law as a force at all" 
(Smart, 1989, p. 12). Her concern here is about finding a radical feminist jurisprudence that neither negates the juridogenic properties of law, nor reinforces the power of law by using its name. Her famous claim is that, "in accepting law's terms in order to challenge law, feminism always concedes too much", meaning that by accepting legal framing of sexual violence, feminist resistance runs the risk of reproducing law's power and ultimately the myths of violence, trauma, and womanhood the movement seeks to challenge (Smart, 1989, p. 5). Smart's (1989) analysis may also fall into the trap of 'conceding too much'. Her analysis of law still imagines law as something ordered and coherent, enough to pinpoint the very ways it functions to silence and curate women's experiences with violence. Smart imagines the order of law as male dominant, and by doing this, suggests a frame that defines law.

There are many other contemporary feminist legal scholars that have followed Smart's (1989) argument. Lise Gotell (2009) argues even with recent shifts to Canadian consent and sexual assault law, legal processes and languages continue to curate sexual violence to fit the ideal victim, but again she proposes a narrative that law can be known as male-dominant, therefore reconstituting the myth that law has an ordered process of framing and representing. For instance, R. v Seaboyer (1991), R. v Ewanchuck (1999), and R. vJ. A. (2011), three foundational cases in Canada's shifting consent and sexual assault law, were deemed feminist victories. Gotell's $(2009 ; 2001)$ analysis argues that these decisions uphold law's power in producing gendered knowledge about sexual assault and victimization. Similarly, Wendy Laracombe (2002) argues that law continues to curate stories of violence. She argues that even in cases of sexual assault that end in prosecution, the ideal victim is still present. Laracombe (2002, p. 131) proposes that in light of 
IMAGINING LAW

"successful" rape complainants there is a new ideal victim, whose characteristics are no longer governed by the "archaic stereotype of the genuine or 'real' rape victim". Rather, she argues that the new ideal victim inhabits the space of neo-liberal political norms and is characterized by ideals of individual risk management and responsibility. Laracombe (2002) argues that the 'new ideal' is produced through gendered and raced constructions of identity, but is imagined as the strong, independent and professional woman with a keen sense of personal safety and self-defense. Gotell (2012) analyzes J.A. (2011) through this lens as well, arguing that the Supreme Court decision which upheld the conviction of J.A. instituted a neo-liberal framework of governance on victims of sexual assault. She emphasizes that J.A. (2011) decontextualizes victims of sexual assault and transforms them into agents of individual choice and responsibility. Law is a frame through which the changing view of modern interpretations of sexual violence are narrated. Both Laracombe (2002) and Gotell $(2001 ; 2009 ; 2012)$ argue that law shapes myths of sexual violence, particularly through gendered narratives of the ideal victim. However, law's power is not only manifested through the curation of sexual assault experiences, it is also present in these narratives of law that give it a way of becoming visible. In Gotell $(2001 ; 2009 ; 2012 ;)$ and Laracombe's (2009) analysis, their conclusions insist that there is a natural way through which law ultimately works, specifically that law works to uphold and establish a gendered and neoliberal subject, which reproduces ideals of rationality and risk management. In their arguments, Gotell $(2001 ; 2009 ; 2012)$ and Laracombe (2009) shape law into something identifiable.

Feminist legal scholarship has not only focused on shifting consent standards in Canadian law to imagine law's power in producing gendered norms of violence. Kristen 
IMAGINING LAW

Campbell (2002) discusses how law constitutes a form of legal memory that produces narratives of gendered truth. For Campbell (2002), evidence and testimony are mechanisms through which law produces notions of reliability and credibility that go on to define gendered roles in law, particularly in sexual assault cases. Campbell (2002) notes that recognition of sexual difference is both a form of judgment and part of building a legal memory that maintains normative gendered ideals. She argues that it is through the “deconstruction of sexual difference as the ground of judgement" that law's constitution of gendered memory can be revealed (Campbell, 2002, p. 175). Campbell (2002) interprets testimony as a form of gendered memory by drawing a relationship between legal assessments of truth, evidence, witness, and gendered constructions of sexual violence. Noting that legal memory is never not gendered, Campbell (2002) considers the cross examination of witnesses as a gendering process that strips women's credibility and reliability. Campbell (2002, p. 170) notes, the trial ensures:

It will be her testimony, above all others, that is called to question. It will be her memory that will be most stringently judged according to notions of reliability, credibility, consistency, and corroboration. It will be her witnessing that will be most subjected to an "evidential" assessment of its re-presentation of event.

Like Gotell (2001; 2009; 2012) and Laracombe (2002), Campbell (2002) agrees with Smart (1989) that law's power produces myths of sexual violence and victimization, and frames the complainant's narrative of violence on the stand through testimony. This scholarship focuses on the ways in which law produces knowledge about sexual violence through decisions, testimonies, and processes. Gotell $(2001 ; 2009 ; 2012)$ and Laracombe (2002), Campbell (2002), and Smart (1989) outline how law curates 
IMAGINING LAW

stories of sexual violence to fit within its framework, but in doing so maintain a narrative that law is inherently powerful in constituting how we understand sexual violence.

Karin van Marle's (2007) discussion of law and time is similar to that of Gotell (2001; 2009; 2012) and Laracombe (2002), Campbell (2002), and Smart (1989) however furthers the discussion by suggesting a separation between art and law. She notes that time in law is fast, chronological, and fails to consider the finer details of memory, specifically memories of trauma and violence. In this sense, law is identified and is perceived to only understand logics of time that are chronological, ordered, and rational. Like Smart's (1989) understanding that law discounts certain forms of knowledge, van Marle (2007) critiques law's processing of time for omitting particularities of memory that transforms recollections of violence into something law understands. Van Marle (2007) proposes that art can be an alternative to law when considering acts of violence, arguing that art is different than law in its ability to allow deconstruction through a more thoughtful experience of time. She considers time in art as slow, lingering, and particular. For van Marle (2007, p. 22) art is a material consideration that "constructs, reconstructs and deconstructs simultaneously and continuously [...] because it disrupts time and the imposed forms of reconciliation curated by law and legal institutions". She (2007) argues that art can be an alternative to law for considering memories of violence because, while law's sense of time is fast and chronological, art's sense of time can linger and give space for reflection, allowing more consideration for the particularities of someone's experience of violence. By making this separation, van Marle (2007) suggests that artistic narrations of violence and trauma are distinct from those found in law. In doing so, art appears as a 
IMAGINING LAW

more authentic method of storytelling because of its slow consideration of details, and law remains as a rational and ordered system.

This scholarship grapples with the ways sexual violence is framed in law. In particular, these scholars argue that law produces myths of victimhood through legal reform, testimony, time, and memory; law curates experiences of sexual violence to fit into the legal framework. However, there are limitations to this analysis. Their focus on law's power in producing gendered norms of violence imagines law as something, meaning that they give law a frame through which it can be known. This scholarship attempts to displace the ways law produces myths of sexual violence, but the emphasis that law is a system of power, and a system that is distinct from art, maintains that it is something knowable and ordered.

\section{The aesthetics of law}

Costas Douzinas (1999) and Adam Geary (2001) connect image, narrative, and law through the idea of the aesthetic spectacle. Their arguments trace how an ideological understanding of law as a universal truth-finding system depends on an aesthetic regime of images and imagination to produce and reproduce this myth. In this way, Douzinas (1999) and Geary (2001) contend that imaginations of law are dependent on aesthetic systems of representation. Law is not singular and imaginations of law can take form in multiple ways. Law is not a stand-alone structure but part of an interconnected system of representation, which, I argue, includes narratives and images in art. However, as Douzinas (1999) suggests, law has come to be known as a system of pure reason without a subject or referent, and this narrative of law has echoed through our representations of it, even when 
IMAGINING LAW

the attempt is to challenge it. While Douzinas (1999) focuses his argument on tracing law through religious iconography and images of modernity, Geary's (2001) argument brings focus to legal imaginations in literature and narrative. James Boyd White (1979) similarly connects the legal imagination to narrative, however I follow Geary (2001) in arguing that White's (1979) analysis does not go far enough and continues to imagine law as a system of reason and truth. Because my analysis of The Ghomeshi Effect focuses closely on the text of the play, I primarily unpack the legal aesthetic of the play through narrative (Ruano, 2016). It is therefore important to understand how narrative is a type of aesthetic and how law can be translated through this form of representation.

Furthermore, I argue that dialogues about the legal imagination maintain an attachment to law, specifically in the notion of social transformation through rights. Using Geary's (2001) analysis of legal interruptions, I critique Drucilla Cornell (2008) and Luce Irigaray’s (1994) conversations of the legal imagination by arguing that their concept of social transformation as collective rights repurposes the myth of universal law. Alternatively, I suggest that activist and feminist considerations of law should consider ways in which their narratives can find interruptions through the aesthetic form without reconstituting the same legal logic.

Douzinas (1999) traces an imagination of sublime law through religious iconography. He (1999) notes that representations of God became less about the sacred subject and more about the idea of the sacred. Imaginations of the idea of the sacred therefore attempted to represent something invisible and elusive. Douzinas (1999) argues that the invisibility of God's power is what makes it most powerful. The censorship of God's image as a subject gave rise to a sublime imagination of God's power; God's power 
IMAGINING LAW

is invisible and cannot be represented, yet this invisibility is what "underpins its mystique" (Douzinas, 1999, p. 52). Despite its invisibility, God's power still takes form through the image. Douzinas (1999) argues that in order to know the sublime imagination of God's power, it must first exist through the image. He argues that in absence of a direct representation of God's power, “images of eagles, peacocks, and serpents" acted as referents for the point of securing the presence of God (Douzinas, 1999, p. 56). In this sense, the aesthetic spectacle of God communicates a sublime and invisible power through the symbolic.

Douzinas (1999) notes that histories of religious iconography made room for the imagination of sublime law as politics focused more on secularization during the shift into modernism. For Douzinas (1999), sublime law is just as much an imagination of self as it is the imagination of law. He argues that sublime law exists while "we imagine ourselves as autonomous and legislating the norms of our subjection" (Douzinas, 1999, p. 57). By saying this, Douzinas (1999) argues that the modern subject is both the idea of freedom from command and right to autonomy, as well as the production of a moral and transcendent law. Law is imagined as reason, "it is pure and without origin or lawgiver" (Douzinas, 1999, p. 57). The imagination of sublime law is universal and absolute. However, this imagination of law, as transcendent, moral, and universal is still attached to the image. In the same way, the presence of God is animated, Douzinas (1999) argues that the legal imagination is illuminated through the image; the image is the form through which we are reminded that law is present. Douzinas (1999, p. 58) states "We do not know what the law is but this lack of knowledge is constitutive of law's operation". Law is a 
IMAGINING LAW

representation. It does not have a shape of its own, yet this is the point of law's power. The image is the form through which law becomes present.

Geary (2001) discusses the survival of law's aesthetic spectacle through the repetition of law in the imagination. He argues that the way legal power survives is through the permeating effects of its aesthetic. He notes that law is personified, existing through memory by "making others remember its name" (Geary, 2001, p. 19). In this imagination, law has no referent; it exists within itself. But this is a myth - law is dependent on memory and imagination. For Douzinas (1999) and Geary (2001) law and imagination are not separate. Rather, they coexist to create an aesthetic spectacle that represents the myth of sublime law through reoccurring images and narratives. In Douzinas's (1999) discussion, the mythical imagination of law is moral, universal and constitutive of the autonomous subject as known through the extension of rights and freedoms. Douzinas (1999, p. 50) argues that pervasive "elaborate iconography created a sense of identity by providing the community with a sublime ideal, made visible through iconic representations", all the while resting in the imagination and in memory. Geary (2001) also acknowledges that law is representational and the power of law takes form through the imagination. To this end, Douzinas (1999) and Geary (2001) link image, narrative, and imagination to the enduring power of law.

Geary's (2001) analysis of law's aesthetic spectacle focuses on a different form of representation: narrative. In The Legal Imagination, White (1973) defines narrative and theory differently. Though he notes that there is no "fundamental difference" between the two, they are still different styles and methods of thought (White, 1973, p. 861). In particular, he describes narrative as "magical, not rational; it is of the world of myth, not 
IMAGINING LAW

science" (White, 1973, p. 862). In this way, he notes that narrative is from the "primitive" or "child's" mind, signifying it as imaginative and playful (White, 1973, p. 862).

Narratives lend to storytelling as they imagine ideas of characters and settings that collectively produce the essence of the story. White (1973) argues that these ideas are never finite. Despite intentions of the author or artist, a narrative is a representation of ideas, a collection of allegories that create the world within the story (White, 1973). White (1973, p. 863) notes that because narratives are representations, storytelling "generates a pressure towards the inexpressible, the inexplicable; that whatever one's original intentions, the story creates a life and meaning of its own as it goes along”. Stories can be read and told in a variety of ways and the meanings attached to them can change and dissolve. The inexpressive within a narrative, White (1973) argues, is the most powerful thing about it.

White (1973) contends that narratives play an essential role in law. Law controls a narrative by producing rational and complete endings. Legal decisions, for instance, are one way law controls a narrative. White (1973, p. 873) notes that decisions are "a reduction of experience to system, a conversion of character into label". White (1973) also notes that narratives are important in establishing the essence of law through juridical speech, decision-making, and the language of conflict. He notes that there is a suggestive and persuasive effect of narrative within the law that maintains an essence of rationality (White, 1973).

For White (1973), narrative and law are distinct. Narrative takes form through the function of play and imagination while law is a system of rationality and truth. However, as I have argued throughout this section, law is not entirely distinct from the functions of the imagination and is known through systems of representation. Therefore, narrative is 
IMAGINING LAW

not a tool of the legal process, narrative is a form of representation through which law becomes present. White's analysis of the relationship between law and narrative produces an ideal imagination of law as rational and universal. As Geary (2001) notes, White's (1973) analysis discusses the lessons that law must learn from literature in order for it to become more open and playful. However, this separation of narrative and law produces an imagination that law begins as rational; it fails to consider the ways in which law is produced through aesthetic forms like narrative.

Geary (2001) unpacks a similar ideological understanding of law as that which is presented in Douzinas's (1999) examination of iconography. Focusing on Nietzche's (2006) Thus Spoke Zarathustra, he identifies a legal aesthetic through narrative. Geary (2001) argues that Nietzche's (2006) aesthetic of law is informed by the same ideas of a universal and sublime law. He unpacks how Nietzche's (2006) will to power, as exhibited through the ethic of friendship narrates an ideal of collective morality while also maintaining individual autonomy. He argues that this collective morality values solidarity and the creation of community which ultimately subordinates the individual to the values of the collective. In this sense, Geary (2001) is tracing similarities between Nietzche's conception of collective values to law. Geary (2001) understands Nietzche's (2006) will to power as a will of law. To this end, he illustrates how attempts to renarrate and find new meanings to the imagination of law maintain its power through the aesthetic spectacle.

The same ethic of collective morals can be highlighted in the work of Cornell (2008) and Irigaray (1994). Sexual liberation is a key theme in some feminist writing about social transformation and the possibilities of law. They argue that law is unable to imagine sexual liberation because it fails to conceptualize distinct sexual identities between man and 
woman. Rather, Cornell (2008) and Irigaray (1994) argue that law's conception of womanhood only exists in relation to man. ${ }^{18}$ In their own ways, Cornell (2008) and Irigaray (1994) turn to the imagination to think about a space in which sexual liberation can supposedly act beyond the structure of law. To this end, the two map an idea of what law ought to be.

For Cornell (2008), law cannot imagine sexual liberation because it is limited in its logic and production of knowledge. For Cornell (2008), justice and liberation occur by acknowledging a universal ideal of gendered transformation. Borrowing Immanuel Kant's (1951) sensus communis, Cornell (2008, p. 21) brings an ideal of collective moral imaginaries and the judgement of beauty to the political, arguing that transformation is the production of an aesthetic ideal:

We are all called to develop in ourselves something like an archetypal or ideal of beauty that would allow us to be in touch with this pleasure... The enlarged community, as large as that of humanity itself, is related to this development, or perhaps more precisely a continual striving toward the attunement of an ideal. ${ }^{19}$

\footnotetext{
${ }^{18}$ This is similar to Smart (1989) analysis of legal womanhood as it exists only in the binary of man/woman.

${ }^{19}$ In Kant's (1951) Critique of Judgement, he speaks of the sensus communis as a collective ideal for what "ought to be" (Cornell, 2008, p. 21). The sensus communis is a system for judgement, which considers a universal ideal of thought (Kant, 1951). For Kant (1951), the sensus communis "gave conventional standards for judgement", specifically judgement on "a unique object that is actually felt and that could be communicated for the purpose of spreading the joy in the imagination" (Cornell, 2008, p. 21). The imagination takes shape through an expression of aesthetic ideas of beauty. The experience of beauty as communicated by the sensus communis is set to "symbolize morality because it appeals to an experience of freedom that is common both to practical reason and to reflective judgement" (Cornell, 2008, p. 24-25). For Kant (1951), an experience of beauty reflects morality, reason, and the collective freedom of the sensus communis. Kant's (1951) sensus communis attempts to communicate an ideal image, (in his case, an ideal image of beauty) found within the imagination.
} 
IMAGINING LAW

However, Cornell (2008) notes that law cannot grasp an ideal of collective moral communities because of limitations present in the legal process. For Cornell (2008), law is unable to grasp the 'psychic space' of the imagination and is therefore limited in its conception of sexuality and personhood. Her limitation of law is that it cannot capture the symbolic realm, unlike the sensus communis, that portrays the collective aesthetic ideals of justice and liberation. To reconcile law's limits, Cornell (2008) describes the imaginary domain as a space for the discovery of sexuate beings. Cornell (2008) argues that the mental space of the imaginary domain is a space where the sexuate being is free and where there is a cognitive acceptance of sexual difference. The sexuate being is an aesthetic iteration of the self as gendered and sexed, located through the imagination and known apart from the Other. Though Cornell's (2008) insistence that the imaginary domain is a space for knowing the plurality of identity of the sexuate being, her construction of the imaginary domain places a separation between imagination and law. Cornell's (2008) separation between imagination and law is similar to White's (1973) separation of narrative and law. This separation imagines law as rational and universal. As well, their separations position law as a system that must learn from the imagination. In Cornell's (2008) discussion, law must learn the subjective and individual intricacies of sexual difference in order to produce a better imagination of sexual liberation.

Irigaray's (1994) philosophy of sexual difference understands law as a creative force in producing cultural and political transformation. She argues that liberation does not begin with law, but a desire for cultural and political change (Irigaray, 1994). Irigaray’s (1994) work reconsiders the importance of sexual difference in constituting liberation for women's sexuate beings. She focuses her argument on prioritizing the desire for a political 
IMAGINING LAW

and cultural shift to recognize sexual difference as an intersubjective performance of man and woman (Irigaray, 1994). That is, she argues for an intersubjective consciousness defining two transcendent sexed subjects existing alongside, rather than in relation to each other (Irigaray, 1994). Irigaray (1994) argues that the purpose for sexual difference is to understand womanhood not as an objective relation to man as developed through phallocentric ideals, but as a subjective experience, separate in body, mind, and consciousness (Smart, 1989). Furthermore, Irigaray (1994) argues that this imagination of sexual difference transcends the place of the Other and marks the possibilities of cultural and political transformation. She notes, "Humanity reaches fulfillment between two genders... a destination involving fulfillment of humanity together with the other gender" (Irigaray, 1994, p. 33). For Irigaray (1994), political and cultural transformation occurs at the site of the imagination. Cornell (2008) and Irigaray (1994) understand the imagination to be a space of freedom that inspires collective ideals of sexual liberation and justice.

In Irigaray’s (1994) philosophy of sexual difference, law plays a vital role in enhancing the cultural and political shift toward sexual liberation. Irigaray (1994) imagines law as a "creative and constitutive" force that does not recognize an a priori ideal of sexual difference, but is able to produce an idea of sexual difference through its authority (Deutscher, 2000, p. 78). Irigaray positions sexual liberation in the authority of law and maintains an imagination of law as sublime, transcendent, and universal. Similarly, Cornell's (2008) imaginary domain involves an ethic of collective morality in her theory of transformation that imagines law as partially constitutive of sexual liberation. For Cornell (2008), the imagination is the true space in which sexual liberation is established. She argues that collective imaginations of a liberated sexual identity can transform legal 
IMAGINING LAW

knowledge. Their use of the imagination is meant to find an alternative framework through which law and social transformation may be rethought. In this sense, regardless of legal restrictions on identity, if sexual liberation is imaginable it still can be achieved. However, in producing a separation between law and imagination, their narrative maintains an aesthetic of law as constitutive, rational, and transcendent and therefore animates the aesthetic spectacle of the power of law.

For Geary, aesthetics still hosts tremendous potential for interrupting the power of law. He sees this potential for interruption in ideas of transformation. Geary (2001) states, "Rather than a vision of law completely transformed, a legal aesthetics could be reinterpreted as an interruption of the dialogue that the institution holds with itself' (Geary, 2001, p. 99). I similarly argue that aesthetic interruptions of law's power should not hold onto imaginations of law's failures or purpose, but should acknowledge how law is narrated, illustrated, and presented as singular, universal, and sublime. The power of law is made present through these imaginations of transformation because they propose a separation between the imagination and law. This separation reaffirms that law is distinct from 'external' systems of meaning making. Rather, I suggest that theories of social transformation should not focus on attempting to find a 'fix' to law, but should acknowledge the ways in which we produce law through narratives and imaginations of its purpose.

\section{Conclusion}

The blog post noted at the beginning of this chapter argues that The Ghomeshi Effect's verbatim script authentically tells stories of sexual violence and gives a voice to victims who have been silenced by law. Psimenatos's (2016) article places a distinction 
IMAGINING LAW

between art and law. She argues that law establishes a culture of silence around survivors of sexual violence because it fails to appropriately respond to traumatic experiences (Psimenatos, 2016); her alternative to the silencing effect of law is art, in particular performance art and the production of The Ghomeshi Effect (Ruano, 2016). In stating that the play supports truth and gives voice to survivors, Psimenatos (2016) puts forward an alternative to her conception of law as a system that re-traumatizes survivors of sexual assault.

This chapter argues that this purported separation between law and art is often overstated. Both law and art are systems of representation, and though they are different frames for communicating knowledge, they both involve a process of curation. Throughout this chapter, I argue that the relationship between art and law is struck through aesthetic engagement. The first section suggests that image, literature, and performance are frames through which myths about everyday realties are produced. However, despite Barthes's (1984) analysis in The Death of the Author, I argue that authorial influence is still important to recognize, especially when analyzing verbatim theatre methods. To claim verbatim theatre as truth sustains myths produced through performance and narrative.

The second section of this chapter engages with feminist legal scholarship and challenges their claims that the power of law is present in the production of rape myths and silencing victims of sexual assault. I argue that law is also manifest through feminist work that gives a frame for knowing law as something, specifically as male dominant, rational, and cohesive. The last section of this chapter argues that interruptions to the power of law should highlight how imaginations of law are produced through representation, and should consider the connection of law, art, and imagination in narratives of social transformation. 
IMAGINING LAW

To this end, I challenge Psimenatos's (2016) statement claiming The Ghomeshi Effect is able to present truth of survivors' stories through performance. Just as in law, where representations of sexual violence are framed through myths of gender and sex, The Ghomeshi Effect is also a representation, framed by narration through performance and the themes that guide the curation of the script. 
IMAGINING LAW

Imagining law: Sexual assault, trauma, and social transformation in The Ghomeshi Effect

\section{Introduction}

Behind clunky metal desks the actors mime mundane work as generic office sounds synchronize their movements. The noises of clacking keyboards, email notifications, and cellphone ringers overlap the jumping beat, signifying a chaotic and rushed environment. The actors continue miming: sorting invisible files, typing invisible emails, and answering invisible phone calls. The layered sounds produce a cacophony of combative rhythms. Within the chaos of the play's opening scene, a woman stops. She clutches her chest and tries to catch her breath. She appears troubled, as if the thought of something has rendered her breathless. The actors around her appear oblivious to her plight and continue their work; sounds of rapid breathing are added to the busy office soundscape. The actors begin to march between the desks, crossing pathways and occasionally bumping into one another. Though the woman's panic from before seems to have disappeared, the rapid breathing sounds continue. The panicked woman comes to centre-stage and begins to speak:

When I was a little girl, I was left alone with my grandfather, and I remember being very scared of him, and this is before my mother had remembered that he had abused her. So, I remember him leading me upstairs to his bedroom, one time when he was babysitting me and I was alone with him, and I remember thinking as we're going up the stairs, this is weird, I don't need to go to grandpa's bedroom [...] And I think, I mean I can never know what his true intention was there, but I wouldn't choose to lead my grandchild to the bedroom if I were a grandparent. You know? With grandchildren, you do things like, you play, make lunch, or whatever. And there was just this sort of unspecified 'we're taking a trip to the bedroom' and so I remember 
IMAGINING LAW

my mother telling me that he told her that I was disobedient, right. And my mother said, “oh I'm glad you're disobedient. (The Ghomeshi Effect, 1, p. 1, Ruano, 2016). The marching continues, each actor begins to speak, one by one:

Actor: I mean, like, I don't want to say that things are getting worse, but in my opinion I actually would carefully argue that things are getting worse.

Actor: Violence against people, but also specifically women, has increased dramatically. I mean pornography is so much more graphic and violence against women $[$ sic $]$ than it ever was.

Actor: On the E-girls site, the RCMP told us that $96 \%$ of the internet now is pornography and over $90 \%$ of pornography is violence against women.

Actor: Which is absurd, right, cause when you think about it, not to be too graphic, but like men - and when I say 'men' I use the term loosely - 13-year-old boys in the back of science class are looking at porn on their phone, and 9 out of 10 videos they see is violence against women. And there is no counter narrative, by which I mean there's no pornography that's, like, you and your partner love each other, here's how you have consensual love-making fun, right, it's all about aggression and domination, and abuse.

Actor: So where are we teaching the opposite, the counterpoint (The Ghomeshi Effect, 3, p. 2, Ruano, 2016)?

As the show continues, the actors tell stories of violence, trauma, and healing. We hear from a woman who was molested by her step dad at the age of 12; a man who recalls the story of abuse when he was a child; an anti-racist activist frustrated with police responses to sexual violence; a correctional officer questioning the categories of mad, bad, and sad; 
a mother whose son has been accused of rape; a circus performer who calls for community accountability; and a unionized employee who lost their job after filing a sexual harassment claim. Each story, though involving different characters, are connected through experiences of sexual violence and trauma.

Opening the play, the scene sets a context for the key theme talked about throughout the performance: the increase of sexual violence against women and a call for social change. However, the play is not only about sexual violence and social change; the play also imagines law. ${ }^{20}$ The play's overall narrative suggests that law curates experiences of sexual assault through the trial process causing a culture of silence and re-trauma for victims of sexual violence. The dialogue of the play suggests that meaningful conversations about sexual violence cannot be held in law because law cannot grasp the emotional and structural intersections of sexual violence, like trauma, gender, and race.

This chapter focuses on analyzing the script of The Ghomeshi Effect to draw out how the play narrates law by speaking to sexual violence, trauma, and social transformation. Through a close reading of the script's text, I ask three main questions: How does the script narrate sexual assault? How does the script narrate trauma? How does the script narrate social transformation? Finally, I analyze how these three themes come to narrate law by imagining law's purpose.

The first section of this chapter analyzes how The Ghomeshi Effect narrates sexual assault and trauma. In the play's narrative, sexual assault and trauma are deeply attached

\footnotetext{
${ }^{20}$ It should be noted that the script of The Ghomeshi Effect refers to law as the 'criminal justice system'. The production uses the term 'criminal justice system' to suggest law at various levels, including the writing and interpretation of regulations and precedence, the processes of trial, the structure of court, policing, and prisons. In my analysis of the script, I understand their use of 'criminal justice system' to mean the intersecting spaces, places, and people of law.
} 
IMAGINING LAW

to the body and mind. The play understands sexual assault and trauma to manifest emotionally and spiritually. Through this narrative, the play suggests that experiences of sexual violence and trauma are structurally contingent on intersecting identities, like gender, race, class, and sexuality. Furthermore, The Ghomeshi Effect suggests that this narrative of trauma cannot be heard by law and that law fails to comprehend the intersections of identity and systemic oppression when it comes to sexual violence, ultimately silencing victims and causing further harm.

The second section of this chapter analyzes the production's narrative of social transformation, which emphasizes the importance of community accountability. The production narrates community through ideals of collective identity. Community, in The Ghomeshi Effect is the people and conversations that bind collective values to groups and spaces. In this sense, the production's idea of community accountability is meant to protect collective values, in particular collective values defined by understandings of sexual violence and trauma that are supportive of victim experiences. The Ghomeshi Effect differentiates community accountability from legal accountability by understanding law as an oppressive institution separate from the values of the community. The script suggests that education and dialogue are important for exposing and acknowledging how law fails victims of sexual violence by communicating collective values of trauma 'outside' the structures of law. This narrative is oriented by an understanding of community as something beyond institutions like law in order to argue that community can inspire more meaningful practices of justice for victims and accountability of perpetrators. However, in this separation of law and community, law is not left behind. The Ghomeshi Effect suggests that with legal reform, law can become a space for victims to tell their stories. Learning 
from community dialogues about sexual violence, the play suggests that law can be 'fixed' by inserting "trauma-informed solutions" into legal processes and languages (Ruano, 2016). To this end, the play's narrative of social transformation imagines community accountability and legal reform as points of change.

The third section of this chapter analyzes how the play's prescription of law's failures also produces a narrative of law's purpose. The Ghomeshi Effect suggests that the purpose of law is to uphold collective values of justice and accountability. In this endeavor however, according to the play, law fails victims of sexual violence because it contorts real-life experiences to satisfy legal processes of cross-examination and evidentiary analysis. The play proposes that these processes produce a logic of legal time and memory that is linear and chronological, opposed to the victim's experiences of time and memory, which the play asserts, is messy and non-linear.

\section{Sexual assault and trauma}

The Ghomeshi Effect narrates sexual assault and trauma as something more than just a physical experience. Sexual assault and trauma are rendered as emotionally driven experiences rooted in the idea that something spiritual has been taken away from the victim:

I do believe sex is sacred, and this is a sacred subject we're talking about. And sexuality is sacred, all of it is sacred. But for me, there was always [sic], violence came along with it, from the get go, and I still carry that with me now, right. People can carry different views, but sex I guess has been viewed as a spiritual union, there's a reason for that, right, and so I've seen sexual assault described as 'soul murder' and I feel like that's what I witnessed with my mother, her soul was 
IMAGINING LAW

murdered and she was trying to get it back and just never could. So the physical departure was actually more of a completion of an act that had already occurred (The Ghomeshi Effect, 17, p. 19, Ruano, 2016).

In this line, the impacts of sexual violence manifest spiritually. The line constructs a separation between mind and body, situating sex beyond the body, as a spiritual experience. The reference to sexual assault as "soul murder" emphasizes that the impacts of violence are intangible, situating trauma as something deeply connected within the body. In another example, The Ghomeshi Effect again perpetuates the idea of sex as sacred:

I think that there is actually a ton of fear there, a very specific fear of messiness, just the inherent messiness of sex, of being intensely vulnerable with another person. That when you're in a room with someone and you are naked and you're just laying yourself bare before them, you just plow ahead and you don't think about feelings and you don't acknowledge the feelings and if you're not acknowledging your own feelings you're not acknowledging somebody else's feelings. And that is an inherently violent act (The Ghomeshi Effect, 20, p. 25, Ruano, 2016).

In these examples, the script narrates sexual violence not as a physical act of violence itself, though that is certainly part of the narrative. Rather, sexual violence has an emotional and spiritual impact on the self. In narrating sexual violence this way, the play suggests that the impacts of violence are subjective and appear spiritually and emotionally, in ways that cannot be measured or seen.

In the play trauma is an extension of violence and takes hold emotionally and spiritually. They further frame traumatic experiences as something deep within, as 
IMAGINING LAW

something connected to the soul that changes perceptions of reality as it is summoned to the surface:

There's a certain peace that arrives with it, just being part of your life, and just being an experience your body and your mind and your heart has had. So you know what I do: when I feel the overwhelming trigger coming up in my body and like starting to take over my mind and starting to change my perception of reality and of the person I'm with, I just say, I want all of it, give me fucking all of it, I just want it all, and it just washes over me, and then acceptance, and then it passes (The Ghomeshi Effect, 20, p. 25, Ruano, 2016).

In the play, emotional facets of violence and trauma manifest in the idea of a "trigger", or memories of violence that overwhelm and overcome the body physiologically and emotionally (Ruano, 2016). In the play, despite their explanation of 'soul murder' as something which takes away from the mind and body, trauma is narrated as something that is brought to the surface, inherently present and constantly enduring within the body. In the script, sexual violence is not one moment, but an event that exists across time and in multiple spaces.

The enduring nature of trauma is further emphasized by situating sexual assault as something that cannot be acknowledged:

Because that's the thing, right - people who've never had to go through any kind of sexual trauma really can't relate, in the same way that I can't relate to what it's like to live in a war zone. I can empathize with it through literature, through news, and whatever, and perhaps that's because of the violence that I saw in my childhood, but I have no fucking clue to know what it's like to live in a war zone. 
And if you've never been sexually abused, you have no clue what it's like. How it affects every interaction you have from that point on, with everyone. Especially if you can't acknowledge it yourself (The Ghomeshi Effect, 3, p. 3, Ruano, 2016).

This character notes the limits of narrating sexual violence in a way that can authentically represent the reality of a violent experience. The character notes that, at most, feelings of empathy can be inspired by representation, though the realities of sexual violence cannot be imagined outside the experience itself. The Ghomeshi Effect's narrative of sexual violence separates it from the physical act of assault. Rather, sexual violence, and in particular the trauma that manifests from an event of violence, is an emotional and spiritual experience that endures across time and space and cannot be grasped through representation. $^{21}$

The Ghomeshi Effect script differentiates the idea of sexual violence and trauma from law by understanding the limitations of representation. The play begins by noting that legal definitions of sexual assault are not comprehensive enough to grapple with the longlasting and enduring effects of trauma. The script questions legal definitions of sexual assault and suggest that legal terms open space for reductive interpretations of sexual violence:

First of all, I have to light a cigarette because this can make me angry. "What is rape," for starters. The fact that we've broadened the term to call it sexual assault is a good thing, but it also leaves other people open to say, "Well, that wasn't really

\footnotetext{
${ }^{21}$ It is interesting to consider how The Ghomeshi Effect uses verbatim theatre to mediate the impossibility of representing trauma. As a method that is theorized to maintain the voices of the victim and the authenticity of their stories, it seems The Ghomeshi Effect is suggesting that their script, unlike law, protects the integrity of victim's stories and experiences with sexual violence and trauma.
} 
IMAGINING LAW

rape." So let's call it something else, and then it's not so significant. Except that it is (The Ghomeshi Effect, 2, p. 1, Ruano, 2016).

Here, the script suggests the word "rape" carries an emotional weight that resonates with the impacts of violence much more than "sexual assault". Although legal changes to the term "sexual assault" were intended to resituate sexual violence away from property law and was ultimately interpreted by feminist legal scholars as a way of correcting the inaccuracies of the legal representations of "rape", the production suggests that law's definitions of "sexual assault" cannot grasp the emotional nuances of sexual violence because it produces a concept of sexual assault as merely physical (Łoś, 1994). The Ghomeshi Effect's narrative of sexual violence offers what is perceived to be a counter narrative to the legal definitions of "sexual assault". The word "rape" in the script is given a separate connotation to "sexual assault", as if to suggest that it is a more accurate depiction of the violence. The production suggests that their ability to tell these stories using the word rape means that their representation is more authentic than legal accounts of sexual assault.

It is not just legal language that fails to grasp the realities of sexual violence and trauma in the play; the script also notes that law understands experiences of sexual assault through the production of the "ideal victim". Feminist legal scholarship has identified the ideal victim as a construct in which law misrepresents and curates victim's experiences (Smart, 1989). Held up against the legal narrative of an ideal victim, which is heavily situated in gendered, raced, and classed constructions of sexual violence, sexual assault victims are often discredited during cross-examination and evidentiary analysis (Smart, 
1989). The production suggests that law creates the ideal victim through factors that include but are not limited to race, gender, ethnicity, and class:

Actor: It also helps if you're white. It also helps if you are at least middle class, it helps if you are not a sex worker, it helps if you are not, you know, if you are not like a stripper, or anything else. You know. That's the perfect case.

Actor: It helps, you know, if you're a virgin before that, or if you're, you know, all these things, like god forbid, you're an Indigenous woman in this country and you get raped. Like, good luck, I'm so sorry - but I don't know how, I don't know.

Actor: I don't know how much more I would have been not believe from the minute of the first responder if I had been any other race, or any other class, or been in any way developmentally disabled, or physically disabled.

Actor: Like, oh my god, oh my god, like I can't, it scares me to think of people who are incapable of even doing what I did, which was very little. I often wonder how much worse it would have been, that little trip inside the ambulance if I had been black, if I had been, you know, an immigrant, if I had been unemployed, you know, or on benefits, if I had been, if I had been a drug addict, if I had been an alcoholic, if I had been...

Actor: You know, my god, if I had been homeless, you know, and then there's the whole other gamut of, I mean, my experience was being assaulted by a man as a 
IMAGINING LAW

woman. But there are so many other possibilities, I mean, gender-wise, situationwise, you know, you know, my God, what if I wasn't even in Canada?

Actor: What if I was in, you know, in a developing nation, where the first responder wouldn't have even cared, or wouldn't have even talked to me, or where the first responder wouldn't have even come, or there aren't any! You know what I mean, like, oaah (The Ghomeshi Effect, 5, p. 4-5, Ruano, 2016).

In this exchange, the play attempts to identify how law perceives victims of sexual violence. However, in doing so the play also reifies the ideal victim. Echoing the notion "if I had been", the play positions the characters as the ideal victim: the white, middle class, cis-woman with a respectable occupation. Positioning the characters in this way may also be an attempt to acknowledge a position of privilege, and while this is what the lines seem to do on their surface, they still hold a narrative that law always effects identity in the same way. The exchange reinforces that law is permanently fixed to recognize an ideal, or "perfect case" (The Ghomeshi Effect, 4, p. 5, Ruano, 2016).

The play also narrates that law uses legal testimonies to produce the ideal victim. Referring to records disclosure, the play comments on the culture of "fishing expeditions" and "whacking the complainant", tactics used by the defense during cross-examination (Smart, 1989; Gotell, 2009). This character notes the difficulties of testifying and being cross-examined in a case of sexual violence:

I mean, in my experience, I was told specifically by the lawyer that I contacted about what I should do after I was raped, and he said, they're going to bring up everything, anytime you've ever been fired from a job, any friend you're no longer 
IMAGINING LAW

friends with and you had a bad parting of ways, they find that person as a character witness, and coworker that didn't like you. I myself have bipolar disorder, so they will bring that up, you know, they will bring up the time you were in the psych ward because you attempted suicide when you were twelve, they will bring up every little thing, anything you ever posted on social media that maybe didn't put you in a very favourable light, could be years ago, could be you don't even necessarily believe their interpretation of it said, but they'll find it, and they'll use it against you (The Ghomeshi Effect, 6, p. 6, Ruano, 2016).

The script suggests that the use of personal details in cross-examination is meant to delegitimize witness credibility. The line suggests that law produces narratives of victims by manipulating interpretation of evidence and testimonies differently than the lived experience of the victim. Cross-examination is narrated in the play as law failing to understand the realities of sexual violence. Law's production of the ideal victim is portrayed as a means to silence survivors of sexual violence by holding their experience against the legal ideal of sexual assault. Cross-examination, according to The Ghomeshi Effect, fails to grasp the nuances of sexual trauma; for instance, this character compares cross-examination of a victim of attempted murder to that of a victim of sexual assault:

If someone were accused of attempted murder, you would not ask the victim of the attempted murder on the stand, so how deep did the knife go, how many times did they turn in, did you consent in anyway, were you feeling suicidal that day, you just, you wouldn’t, right? (The Ghomeshi Effect, 14, p. 16-7, Ruano, 2016).

Here, the character is arguing that law's differential treatment of murder and sexual assault cases exemplifies the flaws in the sexual assault trial. Focusing on the incident itself and 
IMAGINING LAW

the behaviours of the victim overshadows the emotional depths of trauma. Specifically, certain behaviours influence whether or not the individual is placed within the image of the ideal victim, or the deviant woman. In making the comparison between cases of attempted murder and sexual assault, they argue that law is reductive and simplifies experiences.

The Ghomeshi Effect's narrative understands sexual assault and trauma to be emotional and spiritual experiences of enduring loss and overcoming. Law, however, is limited in grasping the emotional because it focuses on the moment of the physical event and curates testimonies of violence to adhere to the ideal victim.

\section{Social transformation}

Social transformation is also an important narrative in The Ghomeshi Effect. Tied to notions of healing after trauma, social transformation in The Ghomeshi Effect is imagined as a sudden, yet long-lasting structural change that provides feelings of peace and acceptance for individual experiences with violence. The play proposes that in order to establish change and peace, stories of trauma must be told and listened to. The Ghomeshi Effect's narrative of social transformation considers community to be the platform through which victim's stories can be heard when law fails to represent their voices. The play's emphasis on community solutions imagines social transformation in part as individual accountability, but also as collective change through education and prevention. The play's actionable solution for changing perceptions and language of sexual violence begins by educating younger generations about violence and consent in hopes of transforming collective values of accountability and justice.

Exchanges about the power and impact of social transformation on the lives of sexual assault victims end the play's story. In particular, social transformation is imagined 
IMAGINING LAW

as a moment of sudden change accompanied by long-lasting feelings of peace and acceptance:

Actor: Sometimes social changes come out of the blue, and it's almost like ice melting in a river from underneath and you don't realize that the ice is thinning, until it just whoosh crackles up, and it's like, holy shit, there's no more ice.

Actor 1: I accept this.

Actor 2: This is part of my life.

Actor 3: And part of my mind.

Actor 4: And part of my body.

Actor 5: And I'm going to let it come.

Actor 6: Because if I let it come, it will pass. And I think that's how I found the peace that I've got now (The Ghomeshi Effect, 20, p.25, Ruano, 2016).

These lines communicate an emotional resolve to the play's narrative of social transformation and is tied to an idea of overcoming trauma. The play produces a concept of healing and overcoming as enduring acceptance and peace. Important to the production's concept of healing are the structural aspects of social transformation:

Actor: Then I realized, people don't want to hear it. You can knock on the door as much as you want. If somebody does not want to open the door then the door's not gonna get opened (The Ghomeshi Effect, 11, p. 14, Ruano, 2016).

Actor: A few years ago in Ottawa there was a woman of colour [...] Stacy Bonds, she was in a police station and she was being, and we see it on video, she is being harassed and sexually assaulted by police officers. There is no doubt in my mind of what that is and what that was. However, that officer is still working, that 
IMAGINING LAW

situation is still happening and what bothers me the most is we're constantly being told that's textbook. That's textbook. Well, fucking take the pages out rewrite them and shove them back in because there is something wrong with the textbook if that is how anyone can be expected to be treated (The Ghomeshi Effect, 8, p. 10, Ruano, 2016).

Using metaphors to communicate their desire for structural change, the first quote alludes to change happening by opening doors to new conversations. Reading the door as a symbol of institutional involvement, social change then becomes contingent on structures like law playing an integral part in opening dialogues. The second quote refers to a 'textbook' and when read as a symbol for the structure of law the quote suggests that change happens by rewriting the language and contents of law.

There are two methods through which The Ghomeshi Effect suggests legal reform is possible: education and conversation. This exchange describes an educational platform for teaching young boys about the effects of sexual violence:

Actor 1: So we come into the classrooms and the goal is really to create a space where they can talk. So in the first exercise we string a line between two chairs, and one end of the string has a card that says Violence question mark, and on the other end would be a card that says Violence period.

Actor 2: And then we get them talking, asking about examples in their own lives, what they think violence is. So typically, and we're talking to boys here, so it's going to be fights, it's going to be murders, it's going to be kidnapping, anything physical, right. So they run through that, and you get them talking, again emphasizing that there are no wrong answers, it's just about having a discussion, 
IMAGINING LAW

and then once they've started running the gamut of physical violence options, we throw in something like, what about bullying, what about cyber bullying.

Actor 3: So then you start to see the gears going, start moving and shifting a little bit their understanding of violence, then we move on to providing them with scenarios $[\ldots]$ so probably the raciest one today was sharing an explicit video, where the girl involved is extremely drunk, and in the comments section there's a girl, it seems to be the girl in the video, asking for it to be taken down.

Actor 4: And you get them to discuss it, and put the card somewhere on the continuum on that string between the two points and explain why they put it there, or why they thought it was appropriate to be there, and give everyone a chance to react and then move on to the next one, so again no wrong answers, we're just trying to gauge reactions from them.

Actor 5: In the end you're left with this pyramid, right - power, intent, and impact - and basically the way that we try to finish the exercise is by showing that wherever along the spectrum you are, there's always dimensions of power, impact, and of intent, in all of the scenarios, and it's really to highlight this idea, this concept that violence is extremely fluid and very subjective (The Ghomeshi Effect, 20, p. 23, Ruano, 2016).

The scene communicates that the goal of education is prevention. The script narrates that prevention through education in younger generations will lead to sustainable change for the future. The play's example highlights that perceptions of sexual violence can be changed by reorienting the language and understandings about violence itself. The script suggests that violence should be understood subjectively and fluidly, highlighting the 
IMAGINING LAW

importance of individual experience and collective responsibilities for prevention and accountability. The need for shifting the language of sexual violence is continually highlighted throughout the play. For instance, dialogue like "black lives matter" and "rape culture" is a way the play puts a focus on an issue:

Like in the way you were saying "black lives matter". It's not like saying, no other lives matter! But it's putting a focus on something. So maybe the term rape culture is putting a focus on something that needs to be focused on. We should talk about this (The Ghomeshi Effect, 3, p. 3, Ruano, 2016).

Here, the term "rape culture" is used to construct sexual violence as exceptional. The character suggests that labelling social issues in this way break the silencing effects of systems, like law. In their line, the character suggests that "rape culture" brings the issue into conversation. Similarly, this character wants conversations of sex to shift, in order to redefine how healthy intimate relationships are spoken about: I want to see survivors have an easier time. And I want to see from a very young age people start talking about intimacy. I want to see intimacy and not sex become the dominant force in our society, because that's how you fix the problem. Of sexual violence [sic] (The Ghomeshi Effect, 6, p. 6-7, Ruano, 2016).

Dialogue and shifting conversations of sexual violence are integral for The Ghomeshi Effect's narrative of social transformation. The play conceives of language to define how we know sexual violence and trauma. The play suggests that reorienting the language of sexual violence requires education and prevention platforms directed at younger generations, which are meant to redefine violence as an individual and fluid experience as 
IMAGINING LAW

seen by the educational programming that mapped the connections between power, intent, impact, and violence.

The Ghomeshi Effect suggests that community is important for hearing these stories of violence. Community is narrated as something other than law, and through which justice and accountability are reimagined through education and conversation: "Accountability is not a criminal justice system. Accountability is community, it's conversation" (The Ghomeshi Effect, 8, p. 10, Ruano, 2016). The play positions community outside law and beyond systems of oppression that produce conditions of gender and race-based violence. Rather, community is interpreted as collective values, which, as they shift, have the power to inspire legal reforms that reflect those values. The Ghomeshi Effect defines social transformation as change to collective values that inspires structural change, like legal reform, and the bringing about of feelings of collectiveness amongst community.

There are some suggestions that community can act as a complete alternative to law. Though there are times where community and collective values are seen to be an important step in attaining legal reform, these lines attempt to displace law, replacing it with community accountability and action:

Actor: We also need to examine how other systems of oppression contribute to the reasons why violence is so normalized within our communities. Accountability is key, accountability that doesn't rely on fucked up systems like the criminal justice system that actively criminalizes indigenous and people of colour and perpetuates this really fucked up cycle of violence that doesn't lead to any change (The Ghomeshi Effect, 8, p. 10, Ruano, 2016). 
IMAGINING LAW

Actor: But as I said earlier, I'm not uncomfortable communicating to my community who isn't, who is and isn't a safe person to associate with and exactly why I feel that way. I came across a person in my community, which is like a clown and circus community, which has a crossover with the fetish community [...] In the blink of an eye, I swear to God, with zero consent, zero fucking communication, out of the blink of an eye, a belt around my neck, with the buckle pressing against my windpipe. At a party with people around [...] And I called him out in front of all those people. And I told people that this happened to me at this party [...] So I think I did my proper, quote, responsibility to other women: the message was received by the right people, and I hope that by communicating my story it protected other people. So I don't need the fucking police. I'm policing myself. I police my own community (The Ghomeshi Effect, 9, p. 11-2, Ruano, 2016).

Education and conversation in The Ghomeshi Effect do have an end goal, namely legal reform. The play communicates a need for legal reform that depends on 'learning' from community effort of accountability and victim justice. Their conception of legal reform holds a desire for an ideal law that is able to provide justice and solace as a resolve to sexual violence and trauma. The play understands education and conversation to be steps in producing legal reforms that reflect new and shifting dialogues about sexual violence:

It's real. It happened to me. It had to be told. It's real. It's not just in the abstract. It's real life. And it's real issues. This is what's happening. There needs to be legal reform (The Ghomeshi Effect, 11, p. 14, Ruano, 2016). 
IMAGINING LAW

In particular, The Ghomeshi Effect suggests that legal reforms should consider ways to openly hear and acknowledge victim experiences, without stories of trauma and sexual violence being renarrated by the legal framework. Rather, the play suggests that "traumainformed solutions", which are meant to invite knowledge about the impacts of trauma on victims, must enter into law's language and processing:

I think an initial step and the most basic step is to ensure that there is some form of 'trauma-informed' solution in the justice system and other reporting systems because they're absolutely not trauma informed right now. If anything they're blind to it and risk exacerbating trauma whenever anyone goes to report. Actually in the US there's an American Bar Association committee based on trauma informed advocacy and so they have a protocol in terms of how they're supposed to interview clients. Yeah, imagine! Right? And it's designed for children, actually, it's great, it's a start, but I think it needs to be broadened (The Ghomeshi Effect, 20, p. 22-3, Ruano, 2016).

In the narrative of the play, social transformation is inspired by education and conversation of sexual violence, trauma, and law, ultimately resulting in changes to collective values and "trauma informed" legal reforms (Ruano, 2016).

These narratives of law and community share something in common: both are considered necessary in protecting collective values. Community is not portrayed here as an institution or a system of oppression. The production differentiates community from law by placing community beyond the impacts of law. In doing so, the play constructs community as a wholly inclusive structure that can protect and represent victim's 
IMAGINING LAW

experiences. Where law fails to uphold collective values, community is produced as a solution; a space for accountability, justice, dialogue, and legal reform.

The Ghomeshi Effect's narrative of social transformation imagines structural change, like legal reform, yet there is also an emphasis that community is integral to ensure collective values are kept intact. It seems the core of their narrative is the idea that collective values must be protected, affirmed, and represented by an ideal law, which provides justice and resolve to victims of violence. These values specifically come through the play's dialogue of sexual violence, trauma and justice, which note the importance of accountability and healing for the well-being of victims of sexual violence, as well as for the sustainability of a collective identity.

\section{Law's purpose}

In the play's narratives of sexual assault, trauma, and social transformation is an imagination of law's purpose. Law's purpose is constructed when the script makes note of the ways in which law fails community and victims of sexual assault. By iterating these failures, the play inadvertently reveals its expectations of law. In The Ghomeshi Effect, law's purpose is to authentically hear and represent stories of sexual violence in order to reflect collective values of accountability. Accountability is primarily narrated as a responsibility of law:

No matter what other indirect ways I may have thought about $[\ldots]$ it does come down to the legal system doing its job and hoping that the legal system makes those points, because how else do you get somebody to answer for their crimes, other than going through it? (The Ghomeshi Effect, 11, p. 13, Ruano, 2016). 
IMAGINING LAW

This character establishes that law's purpose is found through legal accountability. In this sense, the character narrates law's responsibility in "doing its job" and making people "answer for their crimes" as a way of righting wrongs of harms done (The Ghomeshi Effect, 11, p. 13, Ruano, 2016). As well, the script pinpoints a legal obligation to protect and prevent:

The difference, I think, is how do you change those people. Because you're never going to change the Bernardos; they're just, they're a lost cause, they're like mad dogs; you lock 'em up and that's where you keep 'em. It's where you get those people who, there's a chance of changing or preventing, and I think it's more preventing, that's the long term, that's the long game (The Ghomeshi Effect, 20, p. 24-5, Ruano, 2016). ${ }^{22}$

Referring to the Bernardos, the character establishes that there are some individuals that cannot be changed. However, the line suggests that there are many cases where change and prevention are possible, particularly through legal avenues of accountability. The Ghomeshi Effect identifies that law's purpose is to uphold these responsibilities of accountability and protection, specifically when collective values are at risk.

The script also narrates that law is failing to uphold its purpose of justice. For instance, this character questions the meaning of a guilty verdict:

\footnotetext{
${ }^{22}$ In the early 1990s, Paul Bernardo committed a series of serial rapes in the Scarborough area. However, he is most infamous for three specific rapes and murders of three girls, Tammy Homolka (Karla's sister), Leslie Mahafy, and Kristen French, committed by him and his wife, Karla Homolka, between 1990 and 1992. The couple became a media spectacle and the case was widely covered across news media. Bernardo was charged with two counts each of first degree murder, kidnapping, forcible confinement, aggravated sexual assault, and one count of committing an indignity to a human body. In 1995, Bernardo was given a life sentence and was barred from the possibility of parole for 25 years because of the status of dangerous offender. Homolka was charged with two counts of manslaughter and served a 12-year sentence.
} 
IMAGINING LAW

What the criminal justice system actually does for you [sic]. You don't get anything. You don't get money. You maybe get a guilty verdict. And on top of that, you maybe get a sentence. [...] It doesn't fix you. It doesn't make you better. It doesn't make it all go away (The Ghomeshi Effect, 14, p. 16, Ruano, 2016).

In this line, justice is imagined as a way of 'fixing' an emotional state, returning to a feeling from before an event. - yet, what law provides through a guilty verdict does not satisfy the feeling of justice The Ghomeshi Effect seeks to communicate, that is a sense of resolve. Rather, the line insinuates that if law cannot 'fix' or provide resolve to victims, then law has not provided justice to the degree that it should. The lines assert that a legal verdict does not provide the solace needed by victims to heal after trauma, and further suggests that law cannot go far enough in its discussion of sexual assault to allow justice. The script maintains this narrative by arguing that prosecution rates of sexual assault demonstrate that law fails to uphold its responsibility of providing resolve to victims:

I just, we can't, it can't continue, it just can't, you know if we said oh you know $94 \%$ of car accidents go unreported or $99 \%$ of drunk drivers go unprosecuted, right.

So I mean our justice system is failing even on its own terms in that sense because no matter what you think about the credibility of witnesses or liability of a particular piece of testimony, if you have a crime where $99 \%$ regularly go unprosecuted, when the purpose of the criminal justice system is to prosecute crimes that affect society, that are really crimes against society, then we're absolutely failing in an abysmal manner (The Ghomeshi Effect, 14, p. 17, Ruano, 2016).

The Ghomeshi Effect relays a notion that law is failing to protect societal and cultural values of justice and accountability. In saying that law must prosecute crimes that are "really 
crimes against society" is to suggest that to cause harm is to attack the collective values of community or society (The Ghomeshi Effect, 14, p. 17, Ruano, 2016). This argument is founded on the expectation of law to protect - or uphold - societal values. Law is present to protect these collective values, yet, as the lines suggests, is failing and disrupting values of justice and accountability. ${ }^{23}$

The Ghomeshi Effect narrates that law fails to protect collective identities, but it also fails to protect individual victims of sexual assault. According to the script, law retraumatizes, specifically because it does not represent experiences of violence in the perspective of the victim:

So the attorney asked me to describe Jim's penis. And I said it's small. And he said, could you describe it more than that. And I said, no, because it was always in my mouth. And then I said, but I can tell you about the three moles on his belly, I can

\footnotetext{
${ }^{23}$ The Ghomeshi Effect situates collective values in their idea of Canadian identity throughout the show. They describe the exceptionality of sexual violence in Canada by asserting that this violence is other than the national values of tolerance and acceptance. In turn, The Ghomeshi Effect suggests another point of law's failure, allowing Canadian collective values to be altered or disrupted because it has allowed the pervasiveness of sexual violence on Canadian soil. There are many instances where the play assumes imaginations of a pure and civilized Canada by exceptionalizing sexual assault and striking a difference between "developing nations" and "Western" nations (Ruano, 2016). For instance, this exchange deliberates on the vast numbers of sexual assaults in Canada and how these occurrences are other than the values of Canada:
}

Actor: But I have daughters! And I'm super sensitive to this, and, as I was telling you before, I'm super sad that half of Canada's population walks around everyday afraid. That is a huge failing (The Ghomeshi Effect, 3, p. 3, Ruano, 2016).

Actor: If we have 3.5 million women having been sexually assaulted in Canada, THAT'S a rape culture. That means the culture of Canada condones this, which I go, 'No we don't!', and they say it's one in ten, then it's 3.5 million, and we have rape culture. Because it means, somehow in the Western - in the multi-cultural, bilingual, democratic, progressive Canada, we just let women get raped! And that's 'ok' (The Ghomeshi Effect, 3, p. 4, Ruano, 2016).

This exchange uses the term 'rape culture' to punctuate incidences of sexual violence in Canada, noting that this form of harm is other than the collective values of democracy and tolerance in Canada. The script narrates that law fails because the values that define Canadian identity are disrupted by the pervasiveness of sexual violence. However, in framing sexual violence in Canada in this way, the play reifies narratives of civilization and development. 
IMAGINING LAW

tell you the scar above his belly button, and the other scar below his nipple, and then I just went on this diatribe describing Jim's physical presence until the defense attorney stopped me, and then there were no more questions (The Ghomeshi Effect, 7, p. 9, Ruano, 2016).

Here, the line suggests that the narratives of violence during trial fail victims because the details which are most focused on are not reflective of their reality. The play narrates a disconnect between experience and legal representation:

What relevance does it have how traumatized I was? [...] he said, so you don't seem very traumatized. First of all, I'm sitting on the stand in a closed courtroom, staring at the kid who put a gun in my face. I'm totally in shock [...] Secondly, the trauma that I experienced from that event was very specific. I was afraid to go out at night. And the sound of shoes [makes slapping noise] slapping against the pavement as the guy, as the kids ran after me, before they held me up, so the sound of shoes slapping [makes slapping noise again] against the pavement behind me, uh, was, I would go into panic attacks when I heard that. So of course I'm not going to sit in a courtroom sobbing hysterically because that's not my trigger. So those kinds of really specific, how you're supposed to act, how it's supposed to affect you, well what did you do afterwards, and - that should have no bearing on the fact that a kid, this kid, that I'm pointing out in court, stuck a gun in my stomach. There should be no correlation between those questions and the fact at hand (The Ghomeshi Effect, 7, p. 9, Ruano, 2016).

The character questions why their experience with trauma is relevant for their testimony. The sounds of shoes slapping, which for the character is an enduring manifestation of their 
IMAGINING LAW

trauma, is not present during cross-examination. The memory of the event, made visceral through the sounds of slapping shoes, cannot be located in the framework of law. Narratives of violence in law are understood to be narrow and not representative of victim experiences. The line suggests that there is a lack of emotional effect to law and, because of this, fails to understand the realities of trauma. In this example, the character's trigger is unknown to the narratives of trauma in law.

The script draws on ideas of legal memory and time as linear and cohesive. The script notes that law only validates accounts of sexual assault if they adhere to a linear timeline:

I can remember what time my alarm went off, how I did my hair, what I wore, what underwear I wore, the music I listened to in my layover, and the fireworks on the QEW as I took a cab to his house. And I remember the time he hit me in the head so hard that I actually saw stars. Because I didn't know that was a real thing, but it is, a very really thing. And I remember some other things. But I don't remember the sequence of events. I don't remember what day it was. Like I just don't remember. So my brain has done a really good job of blocking all that out. And, what am I supposed to do? So I can go up and say, yeah, this happened to me, and they say 'when"', and I say, well I don't quite remember. Right? Story of every other woman. And then I get called a liar (The Ghomeshi Effect, 6, p. 7, Ruano, 2016).

The character's experience with trauma is defined by details that are not recognized by law. The narrative also suggests that law can only hear stories of violence if there is a chronological sequence of events. Some feminist legal scholars argue that legal memory 
IMAGINING LAW

and time are functions of law's inner logic. Sameena Mulla's (2014) discussion on legal metrics of time reiterates the ways law carries an assumption of power. She states that legal time works chronologically and in tandem with medical and therapeutic metrics of time to produce a narrative of an event. In contrast, Mulla (2014) emphasizes the disconnect between legal time and victim time, noting that victim perceptions of time are messy and non-linear. The Ghomeshi Effect also works with this idea of time, understanding that memories of trauma are inconsistent. Here, the script notes that experiences of trauma cannot be heard in law when they do not adhere to linear and chronological organizations of time and memory.

Integral to the script's notion of memory is the idea of healing. The production suggests that law's chronological construction of time disrupts the process of healing, in part because inauthentic legal representations close the door to victim justice:

I guess in a loose sense I considered court, but I was so young, my brain was still forming, my memories, it's been a slog to try to figure out what happened. Like I would say, if it's a 500-piece puzzle, I probably have like a hundred pieces, and so taking that to court seems like a suicide mission, you know? And I just, I don't want to do that to myself. Though I'm really drawn to the idea of getting justice. And I think that's why that kind of direct justice, like harming him - I've also had fantasies of ruining his life, because in many ways I feel like he's ruined mine. (The Ghomeshi Effect, 14, p. 16, Ruano, 2016).

In these examples, law fails because it does not provide avenues for healing and justice. Rather, law reproduces the causes of harm by reorganizing experiences and silencing stories of violence as they are told by victims themselves. Going through the legal system 
IMAGINING LAW

is seen as an extension of sexual violence. For example, law is suggested to be more harmful than an experience of sexual assault:

Many times you can come to terms with your sexual assault, but coming to terms with a judge or lawyer treating you so heinously, it can honestly sometimes be more difficult. So I didn't pursue charges, and I did it to survive (The Ghomeshi Effect, 6, p. 6, Ruano, 2016).

The use of the word 'survival' suggests the violence of sexual assault is extended to the processes of law. Just as the production calls victims of sexual assault survivors' suggests that law is something that must be endured.

In the play's narratives of sexual assault, trauma, and social transformation is an imagination of law's purpose. The play speaks of law as if it is broken; in the play law is a failing system that has let down victims of sexual violence and has left them silenced and victimized. By constructing law in this way, the play does a double move: the purpose of law is also made clear by establishing its failures. By stating that law has failed to hear victims and represent the values of community, the play reveals that this is also law's purpose. In The Ghomeshi Effect, law's purpose is to reflect community and represent collective values.

Narrating law's purpose in this way also reveals how law is imagined to be. The script makes it clear that law does not currently uphold its purpose, and instead imagines what law could be if only there were legal reform and transformation. This imagination of law is representative of Douzinas's (1999) aesthetic spectacle of law. Specifically, how law appears aesthetically to maintain its power and presence as an ordered system of truth. Law appears in The Ghomeshi Effect as something. In the play, law is produced as a structure 
IMAGINING LAW

with an inevitable order and presence. However, the perception that law has an order and structure is a myth. This myth of law holds an ideological underpinning attached to ideals, such as rationality and truth-finding, that are ultimately symbols of the cultural status-quo. The Ghomeshi Effect's narrative of law is not necessarily an authentic depiction, but a curated ideal that coincides, and inadvertently upholds cultural norms, such as the values of truth and rationality.

\section{Conclusion}

This chapter argues that The Ghomeshi Effect's narratives of sexual violence, trauma, and social transformation reproduces the myth that law is a rational and ordered system of truth. The Ghomeshi Effect argues that the purpose of law is to hear victims of sexual violence and reflect community values of accountability. However, they also argue that though it is the obligation of law to provide avenues of justice, it fails to do so and subsequently causes further harm and trauma. Rather, the play suggests that community can act as an alternative to law and can inspire transformation of collective values of accountability and justice, ultimately influencing future legal reforms.

Opening this chapter is dialogue from the play's beginning and their call for a counter-narrative to messages of sexual violence found in law. Ingrained in this call to arms is the myth of what law could be: an ordered structure of truth. By closely reading the text of the script and drawing out their narratives of sexual violence, trauma, and social transformation, I demonstrate how the play produces an aesthetic imagination of law's and how this narration sustains law's power and place in stories of sexual violence. 
IMAGINING LAW

\section{Curating narratives: Law and community in The Ghomeshi Effect}

\section{Introduction}

In The Death of the Author Roland Barthes (1984) asserts that a text is not just created by its author. He argues that a text is developed through interpretation of the reader and that the author no longer exists. In some ways I agree with Barthes, specifically because The Ghomeshi Effect is separate from the verbatim interviews and is not necessarily a reflection of who was interviewed. However, I disagree with Barthes's assertion that the author is dead. Rather, The Ghomeshi Effect's production team curates the text of the interviews by editing, staging, and choreographing themes into it. In this sense, the themes of the play that I unpack in chapter two are not intrinsic to the text or dependent on my interpretation, but are produced through the staging of the play. The production team, specifically director Jessica Ruano and choreographer Amelia Griffin, absolve themselves from the curation of The Ghomeshi Effect, claiming that the play authentically represents the stories and experiences of victims of sexual violence. However, Ruano and Griffin heavily influence the narratives of the play by curating the performances and choreography. The Ghomeshi Effect's narratives of sexual violence, trauma, social transformation speak volumes not about the realities of sexual assault but about the purposes and failures of law.

By analyzing interviews of Ruano and Griffin, I consider why they claim verbatim theatre to be more authentic than law and to what ends this claim has for representing stories of sexual violence beyond the confines of law. I argue that although the intended purpose of The Ghomeshi Effect is to inspire conversations of sexual violence that may lead to social transformation and legal reform, the play's narrative of law's purpose and failures to authentically represent victim's experiences, echoed in both the play's text and 
IMAGINING LAW

the interviews with its producers, maintain a legal aesthetic that justifies law's power. To this end, the play continues a desire for an old legal order, one that is whole and not broken. In the interviews, the producers outline that their intentions are to provide an alternative forum for telling stories of sexual violence that is distinct from law. However, verbatim theatre is not totally separated from cultural influences. Rather, my analysis of the interviews demonstrates that the play is a curated narrative that hinges on the cultural myth of law as an ordered system of truth.

The director and choreographer of the play uphold a narrative of law that focuses on its failure to fulfill its purpose of protecting and providing justice to victims of sexual violence. In the first section of this chapter, I argue that The Ghomeshi Effect aims to authentically represent victims' stories that remain unrepresented in criminal courts. In a blog post on the production's website, Ruano states that The Ghomeshi Effect's verbatim script acts as a form of "documentary theatre" that recounts stories of violence (tgemarketing, 2016; Ruano, 2016). The idea of a record of recounting for Ruano constitutes a response to law's inadequacy to accurately and wholly document victims' voices. The choreography of the play is considered a method of amplifying the text of the documentary theatre and is perceived to reproduce an emotional subtext not communicated by the words of the script alone. Choreography is used to highlight particular phrases and elements of the script that the producers feel would go unheard during a court case. The verbatim script of the show alongside the choreographed dance and movement during the performance of the play, is intended to give "voice to survivors, using their own words and stories to recount lived experience" (tgemarketing, 2016); the script and the play are therefore designed to be considered together and to be understood as extensions of one 
IMAGINING LAW

another. Legal dialogues of sexual assault are seen to be misrepresentations of victims' realities and experiences. In contrast, the play is considered to be an authentic representation of victims' stories of sexual violence and trauma. This narrative is reinforced in their construction of verbatim theatre providing a documentary voice for victims, through which justice is perceived to be possible.

For Ruano and Griffin, theatre is integral for community-based dialogues and social transformation. Specifically, verbatim theatre is argued to produce counter-narratives to law and opens up possibilities of otherwise silenced accounts of violence. The Ghomeshi Effect, for instance, is one such performance that aims to inspire a shift in understanding sexual violence and trauma. The production's commentary on the need for legal reform understands that one of the primary shortcomings to law is the failure to create spaces for different voices and is subsequently unable to effectively hear stories of violence. As revealed through the interviews, Ruano and Griffin consider verbatim theatre methods to inspire more meaningful and authentic representations of trauma and sexual violence than those capable through law.

The second section of this chapter focuses on Ruano and Griffin's discussion of social transformation. I highlight the similarities between the narratives of social transformation in both the play and Ruano and Griffin's interviews. I suggest that these similarities are a product of authorial influence. Ruano and Griffin suggest that communitybased dialogues about the failures of law have woken up because of the Ghomeshi trial. This type of community-based dialogue, according to Ruano and Griffin, has the potential to inspire legal reform and strengthen alternative systems of justice. In this regard, the social transformation that is imagined through The Ghomeshi Effect bridges community 
IMAGINING LAW

dialogues with legal reform. Through this intersection, Ruano and Griffin imagine the possibilities of a more nuanced trauma-informed legal approached as the end goal and as a solution to a 'broken' criminal justice system.

However, that is not all that is imagined. I argue that this narrative of social transformation reproduces myths of a rational and ordered law; myths that Ruano and Griffin justify as truths in their assertion that the play is an authentic representation of sexual assault. My analysis in this chapter highlights that despite Ruano and Griffin's critique of law, they inadvertently reproduce an ideological imagination of law. In doing so, their claim that verbatim theatre is distinct from law is not wholly accurate; law maintains a presence in The Ghomeshi Effect's representations of sexual violence.

\section{Truth claims}

Part of the producer's intentions with The Ghomeshi Effect is to continue a new conversation of sexual violence (Ruano, 2016). However, Ruano and Griffin also note that the play became an avenue through which victims of violence could find a means of justice in an alternative avenue to law. Their notion of justice is motivated by the idea of representing stories and 'giving a voice' to victims whose stories may otherwise be silenced by law. Ruano and Griffin note that the verbatim theatre style, coupled with dance, presents stories of violence in a way that protects the integrity of victim's language and feelings of trauma. They claim that the production, unlike law, gives victim's space to speak and therefore find justice through dialogue and storytelling.

In the script, sexual assault and trauma is identified as a spiritual and emotional experience that exists deep within the body. For Ruano and Griffin, the body is an important property for communicating stories of sexual assault in The Ghomeshi Effect. 
IMAGINING LAW

Ruano and Griffin both identify sexual violence as something that happens physically. They maintain a separation between mind and body that is present in the script and centralize the body:

G: Sexual violence is not just something that happens to your mind. It more so happens to your body. So, be denying the effects and the presence of the body in these conversations is denying a whole level of conversation and impact (A. Griffin. Interview, January 26, 2017).

$\mathrm{R}$ : Sexual violence is very much about the body, and so it seemed only right to have a show that focuses on, um, the language of the body, and how the body reacts to trauma (J. Ruano, Interview, January 23, 2017).

In identifying the body as central to the conversation of sexual violence, Ruano notes that movement provides a language of its own, distinct from the text or spoken word. Even audience reactions depict movement as a distinct form of communication:

G: We had someone, actually, in the talk back say I am so grateful that you included that because I wish that when I was talking about my own instance of sexual assault that, she's like, I couldn't find the words to describe how I was feeling and I wish I had a movement person to work with to move this out of me, but also be able to speak and communicate what had happened without trying to find words that didn't even exist (A. Griffin. Interview, January 26, 2017).

In this sense, movement presented in the play through dance and staging, is an integral method of communicating the narrative of the play. Ruano notes that movement adds a depth that the text of the script cannot: 
R: When you bring movement to it, it kind of, like, helps you to understand it in a different way, and sort of feel it in your body. And um, yeah I think it just adds quite a lot to it, and it says the things the text can't.

Interviewer: What kind of things?

R: 'Rape' [hits torso with fists, one hand on chest, the other on stomach]. It's, you know we don't say this explicitly, but it indicates it's, um, it's rough, it's violent, and it takes something away from you. It's almost an out of body experience, right, and then something, like, goes away [flutters hands and arms away from torso'. And then we do, 'sexual assault' [hits torso with firsts, one hand on chest, the other on stomach. This time, one fist at a time, pulsing with each word 'sexual' 'assault'], because they're the same thing, right, they might sound different, but it's the same effect. So, I mean, none of that is explicit, right? The people might understand unconsciously, things like that (J. Ruano, Interview, January 23, 2017).

The script communicates contention in the separation of 'rape' and 'sexual assault' in Canadian law. The play's script suggests that the word 'rape' carries a more impactful emotional nuance than legal definitions of sexual assault, making the term more meaningful in conversations of sexual violence. The choreography of each word, however, says something different. The words of the script argue that 'rape' is a more accurate term. As explained by Ruano, movement connects the terms noting that while the two words may hold different connotations the impact of the words 'rape' or 'sexual assault' on the body 
IMAGINING LAW

are the same. In this way, the production uses movement and the body to counter legal narratives of sexual assault that separate acts of violence. Movement provides another possibility for communicating their narrative of sexual violence and trauma.

As well as a form of communication, Griffin considers movement as a way of accentuating or diminishing the stories being told. There are many ways movement in the show takes shape, including non-movement in stillness, expressing a state of shock. For Griffin, portraying stillness is important for grasping experiences of trauma:

G: The mind/body connection and how it impacts both. And non-movement how these things can freeze you and stop you, and you know, your mind may be, like, completely worrying and going and going and going but your body is completely still [...] And if you don't have some sort of buffer zone, um I think it would have been incredibly traumatic to present these stories... and so some of the movements really do amplify what's happening... when they were talking about their trigger and how it's not presenting itself in the court room, of the slapping shoes, in that moment the actors are actually using their bodies to create sound to give an experience of what that feels like. So that's a moment where I chose to amplify that moment. And then he says, you know, I go into panic attacks and everything goes silent and everything freezes except for him. Um, and I hope that that brings people to a sense of understanding and then 'whoa', you know, they come back to the story (A. Griffin. Interview, January 26, 2017).

In her example, Griffin notes how following the movement and sounds of the show presents a visceral narrative of trauma. In the scene, she describes how the choreography brings an understanding to the trigger of slapping shoes and carries the audience in and out of the 
IMAGINING LAW

character's narrative. Griffin notes that missing from law is this visceral and emotional connection to trauma. Stillness in movement and sound is meant to invoke the shock of trauma and the emotional effect of the character's experience. There are other choreographed moments that intend to produce a similar effect for the audience. Breath breaks are placed in the movement of the show, designed to give both actor and audience time to take in and recover from difficult stories:

G: The other thing that I specifically did was give the audience some breath breaks. We kept in the script, or rather Jessica kept in the script, a moment where someone says: "Are you ok?" and then [exhales] he breathes for himself and then he walks off the stage. That's for the actor, 'cause that's really hard to present (A. Griffin. Interview, January 26, 2017).

G: And there's a moment after someone said the whole isn't sexual desire one of the strongest desires [sic]? And it's a very troubling account where they're saying like, you know, they don't remember if they've ever had sex with someone who didn't way to do it, you know. And it's just kind of like, you're really grossed out in the moment, you know. And that person is real, that person said that, and that's a person who hasn't really had an instance of this in their life. But right after that, I was like ok everybody needs to breathe, and the actors are in a very loving clump, and I was like ok you need to take five deep breaths and we need to see all your bodies rise and fall, because we need that. The audience. So even just choreographing the breath and making sure it was there when people needed it (A. Griffin. Interview, January 26, 2017). 
IMAGINING LAW

The movement of breath in these instances is intended to play with emotion, amplifying or dampening affective impacts of the narrative. Even in the opening scene of the play, the sounds of quick breathing are present in the soundscape to create tension within the scene. Griffin notes that the sounds of the show are just as much a narrative as the words and the movement:

G: [...] recurring narrative or grounding sound piece [pause] some sort of soundscape that take us into more of the feeling of the piece. The sounds design, absolutely also is to kind of evoke emotion or to give some space to the words or, um, give people a way in (A. Griffin. Interview, January 26, 2017).

Breath is carried throughout the play, in the movement and sound, intended to invoke an emotional depth to the text. It is these small choreographed moments that are meant to bring a level of authenticity to the play. Ruano and Griffin note stories of sexual violence are more than the words spoken, involvement of the body accentuates the words, through emotion, and allows the audience to accept the stories and their performances.

Ruano and Griffin both understand that movement and staging helps a performance produce an emotional setting of a story. Aspects of theatre, like movement, sound, lighting, and performances produce an affective framing of the stories. Ruano and Griffin claim that the frame of theatre is other than the frame of law because of its emotional capacity. They both speak of ways in which theatre can inspire different meanings in ways that law cannot:

G: I think art can be healing, I think that art can be, can spark another way of understanding something. It opens doors, perhaps, inside your mind and inside your hearts that might not be triggered by dry information. So, theatre, you know, you have the words, you have interpretation of actors, who are real people, who 
think also that these stories are devastating. So, you're receiving it from a human. I think this piece is inherently therapeutic (A. Griffin. Interview, January 26, 2017).

R: You just kind of accept it, and then you're like 'Oh, if all these stories are true, then man this happens really often'. And it's really complicated and, you know, it kind of gets you thinking in another way. I think, especially when it's theatre, especially when it's well performed, like with this amazing cast, you can, it helps to develop a sense of empathy. Because I mean, theatre since the Ancient Greek times has always been very focused on the idea of empathy. And being able to understand people better, and to study human behaviour. That's pretty much been its purpose since the beginning (J. Ruano, Interview, January 23, 2017).

Both suggest that theatre has the capacity to produce fluid narratives and invoke different understandings and meanings. This is unlike their narrative of law that suggests legal processes only hear stories of violence that adhere to legal logics of truth. They separate the play from law by noting that theatre can inspire empathy and other ways of hearing stories of violence that are closed to the legal framework:

G: Getting support from a sexual assault support centre and being believed by your friends, and getting supported by your family, that can bring about another kind of peace that maybe isn't offered by your state, but is offered by your community. And that where our laws and our justice system fails that our communities are starting to pick up and do the work (A. Griffin. Interview, January 26, 2017). 
IMAGINING LAW

In this, there is also an idea that theatre is more human than law, as stories performed and heard through theatre are represented as a reflection of human behaviour. By grasping theatre as more human than law, Ruano and Griffin make a claim that the stories represented through the frame of art are more authentic and meaningful:

G: You know art is a reflection of life. You know, and more often than not I think art reflects, not necessarily more often than not but often, art reflects the struggles (A. Griffin. Interview, January 26, 2017).

R: You're not jumping to the 'oh is it true', 'oh do I believe this', you're not jumping to these kinds of questions when you're watching a play. You're just letting it take hold of you (J. Ruano, Interview, January 23, 2017).

Ruano and Griffin suggest the narratives that come through The Ghomeshi Effect are not a product of the production of the show itself (Ruano, 2016). Rather, in claiming that art reflects life, Ruano and Griffin absolve the play from the effects of curation and situate the narratives of sexual violence and trauma as authentic representations. Their choice to use a verbatim script holds a similar effect. Ruano states that the writers of the script are those who she originally interviewed, not the production company (The Ghomeshi Effect, 2016). The verbatim script is understood to 'give a voice' to victims of sexual assault because the words they speak in the interviews are what is performed. Ruano and Griffin claim that framing the script with movement reproduces an authentic emotional undertone that already exists within the text. However, along with the editing of the interviews to form the script, the choreography of the movement is another way in which the narratives of The Ghomeshi Effect are curated (Ruano, 2016). For instance, the choice to use breath and 
IMAGINING LAW

movement to accentuate words and feelings of the scenes are not a property of words, but are produced as a referent to the kinds of emotions they intend to invoke in the scene. Ruano suggests this when speaking about the importance of theatre:

$\mathrm{R}$ : I feel like in this theatre show, no one is questioning whether or not the stories are true because why would they lie? Maybe I'm lying as the person who put the show on stage, maybe I'm making choices that are biased which is totally fair. I can be that, I mean art is biased. It's definitely not objective (J. Ruano, Interview, January 23, 2017).

Although Ruano acknowledges here that the production of the play is influenced by her creative intentions, she makes a remark that theatre allows for a suspension of disbelief in a way that law cannot. Although she acknowledges that art is subjective and interpretive, The Ghomeshi Effect seems to contradict this by claiming that verbatim dance theatre style can inspire an authentic reading of the stories being performed.

Ruano and Griffin separate art and law through emotion. Dance and theatrical staging is understood to produce an affective framing, which it does. However, Ruano and Griffin emphasize that it is this affective framing that allows for an authentic representation and is the very thing law lacks. For Ruano and Griffin, law is emotionless and it is for this main reason that they claim law cannot hear or represent experience of sexual violence.

The claim that The Ghomeshi Effect is authentic masks how much influence the producers have over the play's performance Represented in The Ghomeshi Effect is not necessarily an authentic narrative of victim experience, but stories about sexual violence, trauma, and importantly, truth. As they speak of theatre "taking hold" and reflecting life, Ruano and Griffin uphold myths about the possibilities of finding and representing truth. 
IMAGINING LAW

Ruano and Griffin marry emotion to the concept of authenticity, suggesting that feeling connected or in relation to a character or story proves a level of authenticity. However, looking to Barthes's analysis of photographic framing, emotions are not necessarily a signifier of truthful representation. Rather, they are representative of the frame through which the stories are presented. In this case, the verbatim theatre style used by Ruano and Griffin in The Ghomeshi Effect does not mean that victims' stories are accurately represented. Ruano and Griffin's influence in curating the script is still present, as seen in the affective framing of the text through movement and theatrical staging.

\section{Turning points}

The production team notes that, as a social phenomenon, the Ghomeshi effect describes the impacts of Ghomeshi's trial. The production notes on their website that choosing the title The Ghomeshi Effect was in no way to insinuate that the play is about Ghomeshi (Ruano, 2016). Rather, the production asserts that the title is meant to refer to "stories of other individuals in Canada who have had a variety of experiences, both positive and negative with the justice system" (tgemarketing, 2016). Subsequently, the title is used to reference the way in which conversations of sexual violence are formed in Canadian news and social media coverage. Much of this coverage includes an outpouring of support for the victims, as well as explorations of the language and dialogue of sexual assault in Canada, exposing a 'turning point' in a larger, social understanding of what sexual assault is and how the justice system is supposed to respond. The term, 'the Ghomeshi effect' is defined by Ruano and Griffin as the need for community involvement in order to provide support and justice when the law fails. Ruano and Griffin note that the impact of the trial 
IMAGINING LAW

and the Ghomeshi effect has greatly shifted the conversation of sexual violence in Canada. Ruano and Griffin's discussion of the term reveals that they perceive that Canadian imaginations of community and law were shattered as a result of the Ghomeshi trial, and that the play has inspired a desire for collective identity and an ideal law. They identify the 'turning point', or point of waking up, as the entry of law into the discussion of sexual violence:

Ruano: I think it [Ghomeshi trial] raised a lot of awareness about how the legal system functions, um about what type of person is a credible witness, about what constitutes "normal" behaviour following a sexual assault, and normal is in quotation marks (J. Ruano, Interview, January 23, 2017).

Very similar to conversations of credibility and the ideal victim presented in the play's script, Ruano notes that law's construction of credibility and witness behaviours are now at the forefront of sexual violence dialogues. She furthers her analysis of the Ghomeshi effect phenomenon by suggesting that the impacts of the conversations post-trial have opened up dialogues about sexual assault experiences, in turn, closing doors to criminal reporting:

R: I think it has also had an effect in two rather contradictory ways, or arguably contradictory, in the sense that since this trial more people have been speaking out about their sexual assaults and their experiences with sexual violence. There are more people coming forward. But conversely, fewer people actually wanting to report, um, what's happening to them. And by report, I mean going to the police or pursuing criminal charges (J. Ruano, Interview, January 23, 2017). 
IMAGINING LAW

Ruano's explanation about the impacts of the Ghomeshi trial suggests a split between legal and community dialogues. For Ruano, the trial exemplifies the drawbacks to criminal reporting and the limitations to legal methods. The Ghomeshi effect, in this sense, identifies what Ruano and Griffin see as the limits of legal methods in hearing cases of sexual assault. Similarly, Griffin speaks about the Ghomeshi effect exposing underlying impacts of violence:

Griffin: [The Ghomeshi effect] is a point of waking up [pause]. It's a point where we could no longer just turn a blind eye to this, which is unfortunately what has been happening for ever and ever in the past [pause]. I just feel like it was a really [sic], a turning point in busting open what's happening, you know, in the background and underneath everything. Sexual violence, I think, has been happening since day one of human kind [laughs], you know and it has taken us this long to open up (A. Griffin. Interview, January 26, 2017).

Griffin asserts that sexual violence, as something normalized and reoccurring, has never been a point of dialogue. Griffin aims to open up space for more direct dialogue on sexual violence. She suggests that, recently, the dialogue has shifted to expose the impacts of sexual violence, particularly in social spaces such as the media.

Another essential element of Griffin's calls to 'wake up' pertains to national identity:

G: This massive turning point in sharing and talking has really forced Canada to have a look at itself and that maybe our laws aren't actually upholding the identity we identify with (A. Griffin. Interview, January 26, 2017).

Griffin places the Ghomeshi effect's impact in an idea of Canadian identity. She notes that the conversations inspired by the Ghomeshi trial raise questions about collective identity: 
G: I think part of the reason why it blew up, or why people woke up, is that they also felt a bit, um [pause] let down by this man who presented himself as a man of the people and spoke for Canadians. Not so much spoke for Canadians, but was a voice of Canada [...] I think it's hard for Canadians because our identity is so much wrapped around being 'nice', and when someone from our community who we're proud of and who is representing us doesn't act in a nice way I think that really has people questioning our collective identity of what that means (A. Griffin. Interview, January 26, 2017).

Griffin interprets the Ghomeshi effect phenomenon as the point where conversations of sexual violence have 'woken up' in the Canadian imaginary. Both Ruano and Griffin's explanations of the effect propose that the Ghomeshi trial has shattered an ideal imaginary of law and collective identity. For Ruano, the Ghomeshi effect rethinks law as a space of protection and justice and suggests that law distorts experiences of sexual violence and should be reformed to better represent victim's stories. For Griffin, the effect questions the security of a Canadian collective identity. Understanding this claim in relation to the script's narrative of a broken legal system and the search for community justice, Ruano and Griffin uphold a notion that law exists for the preservation of a collective ideal of justice. In this sense, the impact of the trial and the emerging phenomenon of the Ghomeshi effect is not only about a growing conversation of the impacts of law on sexual assault victims. The term reasserts the myth that law's purpose is to protect and govern collective ideals of rights and justice. Griffin even refers to Ghomeshi's name as a place marker for Canada: 
IMAGINING LAW

G: It [The Ghomeshi Effect] was really to place it, both in time and as a Canadian play. And as well as a turning point for conversation [pause]. So I really think the phenomenon is the start and the spark of Canadian based conversations, by Canadians with Canadians, surrounding the handling of these types of cases (A. Griffin. Interview, January 26, 2017).

Griffin argues that the use of Ghomeshi's name was not to insinuate anything about him, but to set the scene for Canadian based conversations. Ruano shares this idea about the title, claiming that naming the show with his name is a reference to the phenomenon of developing conversations:

R: Let's say I called the show Been Raped, Never Reported, right, which maybe would have been another apt title, um, that's not all the show is about. And it's not just about those stories [pause] I think the show is definitely a damning account of the legal system, for sure, just based on the interviews I did, because you know, I wasn't seeking that, that's just what came to me. I felt like The Ghomeshi Effect was not making a statement as a title, or not making a statement about Ghomeshi's trial. We're not saying anything about him as a person, we're just saying that this trial happened, it had an effect, and look how many people are having this conversation now, and speaking about it really openly. It was more just an acknowledgement of our current cultural climate [pause]. The effect is meant to intrigue people and bring us to the play [pause] to describe the phenomenon of conversation and questioning post-Ghomeshi trial (J. Ruano, Interview, January 23, 2017). 
However, The Ghomeshi Effect does make a statement about the development of a collective identity. In my interviews with them, Ruano and Griffin argue that narratives of law and collective identity built through the play are attached to Ghomeshi's name. Ghomeshi is intended to signify post-trial reactions and the development of Canadian based conversations. However, more significantly the title does a lot more to solidify the play's narratives of the failures and purpose of law. Ruano claims that, despite the show's title using Ghomeshi's name, the show does not say anything about him or his trial. However, the positioning of Ghomeshi, who is widely associated through accusations of sexual assault, frames signifies that the stories told in the play are those that are not heard in law. The title makes a statement that law has failed to hear and protect community values about accountability and justice. $^{24}$

\footnotetext{
${ }^{24}$ Another way of thinking of this is acknowledging how the play places Ghomeshi, an Iranian-Canadian man, as the subject line of these conversations of sexual assault. The placement of a racialized name in context of sexual violence maintains constructions of the racialized male perpetrator in cases of sexual assault Kimberle Williams Crenshaw (1997) analyzes the intersections of race and violence in popular culture, looking at various obscenity charges that banned 2 Live Crew from performing in Florida in the 1980s. Her analysis discusses the impacts of obscenity doctrines that seek puritanical interests of protecting "community sensibilities" and therefore subjected the rap group to prosecution over lyrics that suggest the violence abuse and rape of women. Crenshaw acknowledges that the lyrics in these songs certainly carry alarming messages, particularly for those who actively work on issues related to gender violence. However, what troubles her more is the response declaring the songs obscene, and subsequently categorizing 2 Live Crew within images of black male violence. Furthermore, she suggests that these reactions that inspired the ban and prosecution of the group did nothing to acknowledge those who may be directly impacted by the 2 Live Crew's narratives, black women. Rather, she argues that the puritanical base for the obscenity charge furthers the invisibility of black female representation and the production of racialized men as the subject of violence. Similarly, Ummni Khan's (2017, p. 27) analysis of feminist protests to "rapey songs" as examples of "rape culture" understands that these reactions fetishize "the language of censure" as well as the image of violent black men. Khan (2017, p. 25) suggests rather than reading these songs as literal instances of violence, which narratives of "rapey" and "rape culture" are derived, they should be considered as "art and as fantasy". To this end, she argues that these songs, thought about through a kink framework, can open avenues for analyzing violence through role play. Centralizing Jian Ghomeshi's name as the subject about a play that is intended to expose "rape culture" in Canadian law produces similar narratives of race and violence.
} 
IMAGINING LAW

As it is also narrated in the play, Ruano and Griffin suggest that community is an alternative to the closed off legal framework. For Ruano, community is established through open dialogues:

R: I think community is conversation. I think it's having these open dialogues. I think it's, you know, even if it's just with your close friends or the entire classroom, just to be able to speak openly about it and not feel like it's all on you because $[\ldots]$ if there is anything I know from these interviews a lot of people have had similar experiences and that only if they could find each other, that would be so instrumental to their healing (J. Ruano, Interview, January 23, 2017).

Griffin considers community differently, structuring it as a collective of people. Although they have different considerations of community, both suggest that community is important for stepping in where law fails. Specifically, in protecting and providing justice:

R: If we're not getting justice and balance and peace from our systems, then it becomes vital that our friends, family, community organizations, and society as a whole find a way to move in and provide that, despite what's happening. It's the most important thing (J. Ruano, Interview, January 23, 2017).

G: Getting support from a sexual assault support centre, and being believed by your friends, and getting supported by your family, that can bring about another kind of peace that maybe isn't offered by your state, but is offered by your community. And that where our laws and our justice system fails that our communities are starting to pick up and do the work (A. Griffin. Interview, January 26, 2017). 
Ruano and Griffin separate law and community by noting that law's failure to uphold its purpose incites an obligation of community to provide the justice and support that law cannot. The separation of law and community, which is also present in the script, is an intended narrative.

Community dialogues about sexual assault that are supposedly rising from the impacts of the Ghomeshi effect are important to their conversation of social transformation. In particular, The Ghomeshi Effect is aligned as a community outreach effort for the purposes of continuing the conversation of sexual violence and law post-Ghomeshi. Following each performance, The Ghomeshi Effect presents a talk back series entitled TGE Dialogues that includes a series of panel talks with community partners on sexual violence, law, and trauma (Ruano, 2016). The panels include OCTEVAW (MANIFest Change), ComingForward, SASC Ottawa, defense lawyer Helgi Maki, and keynote speaker Glenn Canning (father of Rehteah Parsons). Each talk discusses the impacts of sexual violence and trauma on victims, the limits of the legal system in hearing cases of sexual assault, and the possibilities of social change through community involvement beginning with the education of youth about the importance of understanding consent and the nuances of violence. TGE Dialogues is framed as the show 'giving back' to community organizations by providing spaces for awareness, education, and conversation (tgemarketing, 2016). The TGE Dialogues series is one way through which the play aligns itself as a grassroots community organization. The production's website notes:

More than a production [The Ghomeshi Effect] is a grassroots initiative by Perspective Collective Theatre (PCTheatre) to unite existing social justice 
IMAGINING LAW

organizations and find creative ways to end gender-based violence through performance and outreach (The Ghomeshi Effect, 2016).

The production team of The Ghomeshi Effect frames the play as more than theatre, asserting that it is a driving force for social change, political activism, and community development. In particular, the play is considered a feminist political voice in the conversation of sexual violence. Ruano and Griffin note the play's political attachments to the feminist movement:

R: I think feminism is, um, well it's a bit like how I'd describe the show actually. It's sort of an acknowledgement of the way things are, and looking towards how they could be. And actually, being active in terms of making changes. So, I think it's to acknowledge that men and women are not currently equal, we've definitely made some amazing strides, but there's still work to be done (J. Ruano, Interview, January 23, 2017).

G: This is why I say [feminism] is everywhere and nowhere because I don't think you can say at any particular place in this piece "oh that's a feminist moment", you know. I think just it comes from our perspective. This is how we see the world and this is also how we want the world to move forward (A. Griffin. Interview, January 26, 2017).

Their descriptions of feminism focus on the possibilities of social transformation. Integral in their processes of feminism and social change is the practice of art. Especially Ruano who perceives feminism as "a critical approach to art", the play as a feminist commentary of law and sexual assault is considered a political act: 
IMAGINING LAW

R: I think sharing stories is a political act, and the medium of the show reflected its message: that we need to talk about this, that we need to openly. And if we can only do it through anonymous confidential interviews, then sure let's start with that (J. Ruano, Interview, January 23, 2017).

Ruano states that dialogue, particularly storytelling, is a political act. Connecting to the play, Ruano refers to the script of The Ghomeshi Effect, insinuating that the verbatim script of the play can act as a political vehicle for story-sharing and social change (Ruano, 2016). The Ghomeshi Effect website echoes this claim about theatre's political potential to inspire community based change:

PCTheatre believes in art as a vehicle for change and has already taken steps to continue this important conversation around sexual violence and the justice system, such as workshopping the show material in Ottawa high schools (The Ghomeshi Effect, 2016).

The play is considered more than a performance. The Ghomeshi Effect is constructed as a piece of political art, through which dialogue and community development can lead to social transformation.

Ruano and Griffin note that in the spark of the Ghomeshi effect phenomenon, feminist social transformation maintains a clear goal: that is legal reform and changing community perceptions of sexual assault. They perceive a linear trajectory of transformation, characterizing a before, an after, and a time of transition. Griffin notes that the Ghomeshi effect phenomenon is part of this transition:

G: I think [the Ghomeshi effect] is trying to achieve change in the justice system. I mean, as you know, and as I found out through this play, that rape doesn't even 
IMAGINING LAW

exist in our laws. And people are finding that out through our play [pause] that there's sexual assault one, two, and three and how, um, and how that's not even the truth, you know? I think we're at a point where, in our general society and communities, where the first step is to say I believe you, and listening. That's been sort of the active way, like we were saying earlier what's the before and after? I think right now people are like, you that's what I need to do (A. Griffin. Interview, January 26, 2017).

Griffin notes that there has been a point of identifying what needs to change, specifically law's definition and framing of sexual assault. Griffin understands that change is inspired through open dialogue, something she perceives is The Ghomeshi Effect play's overall impact:

G: And I've had many people write to me and say you know, I'm going to be talking about this, the play but also the subject matter, to everyone. We've done our job. The conversation, that's what we want. We're there also as a grounding force. So, that brings me immense joy, you know? It's like through the shit, comes the flower (A. Griffin. Interview, January 26, 2017).

There is a clear idea of what transformation should look like. For Ruano, transformation is legal reform and the introduction of trauma-informed advocacy into legal conversations:

$\mathrm{R}$ : The ending narrative is trauma informed advocacy and how we move forward. And yeah, perhaps these things aren't going to stop, but through education and knowledge of how trauma is understood interpersonally and in our justice system that perhaps there's hope to move forward (J. Ruano, Interview, January 23, 2017). 
IMAGINING LAW

Griffin also sees transformation in legal reform, yet for the purposes of ensuring justice and protection for victims. In her statement, Griffin further reveals a desire for a return to a legal order that is naturally good and protects the people and values of community:

G: I think [justice], and I thought this before I thought of the scales, but I think it really does have something to do a lot with balance. And I think that, I've mentioned in the play, and what I really feel is you don't really get much from the justice system. It's not like you're getting a settlement, it's not like you're getting you know, um, the person might not even say sorry. Like, you're not really getting much. I guess when balance is restored to a place where you can find peace. And I don't think that the way that things are currently set up, that they should even be using the word justice for these kinds of cases because there's no balance there and rarely do people find peace. But I think seeing something done, at least to stop it happening again, or know that that person won't harm you again, that you've been protected in come capacity. And it pains me to think that so many people aren't protected, aren't offered any kind of protection and support from our judicial system (A. Griffin. Interview, January 26, 2017).

Trauma informed advocacy, a method regularly used by peer support programming in rape crisis centres, acknowledges the impacts of trauma on victims. The Ghomeshi Effect suggests that legal proceedings, definitions of sexual assault, and the treatment of complainants will be better informed through community dialogues of sexual violence (Ruano, 2016). Ruano and Griffin make the claim that law fails to inspire transformation and uphold community values because their idea of transformation is getting law to learn from community dialogues to inform the solution to a broken legal system. Like the 
IMAGINING LAW

narratives of law in the script, Ruano and Griffin imagine law as a broken system that fails to protect and provide justice. They determine that a need for transformation is found because of this failure as victims of violence are silenced and collective identities are questioned. Ruano and Griffin identify a new dialogue about sexual violence and the criminal justice system ‘waking up' post-Ghomeshi trial. This new conversation, a product of the Ghomeshi effect, is considered the beginning of a new imaginary of social transformation, beginning with the rise of community dialogues and leading to an ultimate goal of legal reform. However, as I have argued, the Ghomeshi effect is not the beginning of a new imaginary of social transformation, but a desire for a mythical ideal of a rational and truthful legal order.

Through The Ghomeshi Effect, the producers have not grasped an authentic representation of victim experiences, but an animation of an ideological imagination of law that reproduces a myth that law as rational and ordered. Rather than providing a forum of storytelling outside the legal order, The Ghomeshi Effect's representations of sexual violence and aesthetic engagement with law reproduces these myths and naturalizes them as truths.

\section{Conclusion}

The intention of The Ghomeshi Effect play is to continue a supposedly new conversation of sexual violence inspired by the Ghomeshi trial. The Ghomeshi effect phenomenon is defined as the 'turning point' of dialogues about sexual violence and its intersection with the criminal justice system. The play is meant to echo these conversations.

The director and choreographer of the play reveal that the production has a much more resounding impact. They claim that the play has woken up community-based 
IMAGINING LAW

dialogues of sexual violence and law that have opened space, not just for conversation, but also for justice. They argue that the new era of conversation has illuminated the ways in which law fails its purpose of protecting collective values and has closed doors to victims seeking justice through law. Furthermore, they argue that community has become an alternative to law for hearing stories of violence and providing the support that law cannot.

Ruano and Griffin claim that the play itself, through the verbatim script and choreographed dances, is a platform for justice as victims' stories are authentically represented by The Ghomeshi Effect's emotional and empathetic performance. They claim that it is through authentic representations, such as those in the emotional framing of dance and theatrical staging, that collective feelings of balance and justice are found.

However, these constructions of justice, community, and theatre say so much more about The Ghomeshi Effect's imagination of law. Making a distinction between community and law, as well as theatre and law, Ruano and Griffin note that community and art has had to step in to fulfil a purpose law has failed to uphold. In particular, their imagination of law suggests that its purpose is to uphold collective ideals of justice. By producing this narrative through The Ghomeshi Effect, they imagine law as universal and transcendent.

There is also a production of the myth that law is a system of truth. Ruano and Griffin claim that The Ghomeshi Effect authentically represents victim's stories and in doing so provides an avenue for justice (Ruano, 2016). They argue that the play's representations are an alternative to law because it can genuinely communicate stories told. They seek for art to fulfil law's purpose, presenting their performances as truthful or authentic reproductions of victim realities and experiences. These imaginations of law are 
IMAGINING LAW

myths that are reproduced and naturalized as Ruano and Griffin absolve themselves from curating the play's narratives and situate them as truths. 
IMAGINING LAW

\section{Conclusion: Aesthetic interruptions}

It has been several months since The Ghomeshi Effect performed its closing night. Nearly every performance was sold out and, at least during the two I attended, they received standing ovations. There is no doubt that creating effective theatre takes a lot of work. Aside from critics remarking on the difficulties of staging the show, in general the play was well received. Many commended The Ghomeshi Effect's producers for breaking institutional silence with the play and giving a voice to victims of sexual assault. The support for the play indicates two possibilities: The Ghomeshi Effect and its producers have made an impact on conversations of sexual violence by introducing a critique of law, and the play has given victims a voice and a space for justice. Alternatively, the positive reception can indicate that these feminist narratives of sexual violence continue to reproduce ideological imaginations of law. I argue the latter; The Ghomeshi Effect is not a space of authentic representation of sexual violence, but an aesthetic platform through which law is inadvertently animated.

While I do not question any of the stories of sexual assault and trauma told for the purposes of the play, I do argue against the producer's claim that representations of sexual violence performed through verbatim theatre are necessarily different than law. The producers curate the play by organizing the interviews, choreography, and staging to present the stories within a frame that they have created. The stories told through the play are not representative of individual experiences, but of narratives of sexual assault, trauma, and social transformation intended by the producers. Furthermore, I argue that these intended narratives inadvertently communicate an imagination of law, one that is grounded in myths that law is knowable as an ordered system of truth. The producers separate the 
IMAGINING LAW

play from law, suggesting that the play's ability to authentically represent makes theatre a more meaningful platform for discussion.

I use Douzinas (1999) and Geary's (2001) conceptions of legal aesthetics to argue that law, rather than being a fixed institution, is a representation produced by our imaginations of it. In this sense, there is no one space that law exists; it is animated by our images and narratives. To show this, I turn to the script of the play and detailed research interviews with its producers to examine how the play narrates sexual assault, trauma, and social transformation, how the producers have influenced those narratives through curation. Finally, I consider what ways these narratives produce an imagination of law. I found that their narratives of finding alternative avenues of justice through community accountability reveals their assumed purpose of law: to protect collective morals and provide justice to individual victims of sexual assault. By doing so, the play continues to animate an idea of law as naturally rational and ordered.

There are many possibilities for thinking about the aesthetics of law. For the purposes of this thesis, I could only look at one piece of art, yet there are many more. When approaching The Ghomeshi Effect I thought it was best to focus my analysis to the play and its producers in order to show how the producers have curated and influenced the production. However, future research could compare narratives of sexual assault, trauma, and law in the script to those in the transcript of the Ghomeshi trial. This comparison could further trace ideological and cultural influences that connect law and art and sustain myths of an ideal law.

Through my analysis of The Ghomeshi Effect, I have demonstrated how the power of law can be aesthetically represented in narrative. Yet, despite law's attachments to 
aesthetics, art still holds tremendous possibilities for interrupting its power. Feminist resistance through art should reflect on the ways law is presented. As Geary (2001) notes, interruptions should not desire an old legal order, rather new imaginations of law should be made. Feminist activist engagements with art have the potential for the creative interpretations needed for this, but it will take a thoughtful and meaningful change in how law is imagined in relation to ourselves and the world. 
IMAGINING LAW

\section{References}

Babbie, E., \& Benaquisto, L. (2010). Fundamentals of social research (3rd ed.). Toronto: Nelson Education.

Barthes, R. (1957). Mythologies. Translated by Annette Lavers. London: Vintage.

Barthes, R. (1980). Camera lucida. Translated by Richard Howard. New York, N.Y.: Hill and Wang.

Barthes, R. (1984). Image, music, text. London: Flamingo.

Campbell, K. (2002). Legal memories: Sexual assault, memory, and international humanitarian law. Signs, 28(1), 149-178.

Carlson, M. (1996). Performance: A critical introduction. New York, N.Y.: Routledge.

Cornell, D. (2008). Moral images of freedom: A future for critical theory. Lanham, Md.: Rowman \& Littlefield.

Coughlin, Anna M. (1995). Regulating the self: Autobiographical performances in outsider scholarship. Virginia law review, 81(5), 1229-1340.

Crenshaw, K., W. (1997). Beyond racism and misogyny: Black feminism and 2 Live Crew. In Diana Tietjens Meyers (Eds.) Feminist social thought: A reader. New York: Routledge.

Derybshire, H., \& Hodson, L., (2008). Performing injustice: Human rights and verbatim theatre. Law and humanities, 2(2), 191-211.

Deutscher, P. (2000). The declaration of Irigarayn sexuate rights: Performativity and recognition. In Janice Richardson \& Ralph Sandland (Eds.), Feminist perspectives on law and theory (pp. 71-88). London, U.K.: Cavendish. 
IMAGINING LAW

Douglas, S. (2016). Constitutions are not enough: Museums as law's counter-archive. In Stewart Motha \& Honni van Rijswijk (Eds.), Law, memory, violence: Uncovering the counter-archive (pp. 140-155). New York, N.Y.: Routledge.

Douzinas, C. (1999). Prosopon and antiprosopon: Prolegomena for a legal iconology. In Costas Douzinas \& Lynda Nead (Eds.), Law and the image (pp. 36-67). Chicago, Il: Chicago.

Eco, U. (1977). Semiotics of theatrical performance. The drama review, 21(1), 107-117. Foucault, M. (1978). History of sexuality vol. 1: An introduction. Translated by Robert Hurley. New York, N.Y.: Random House.

Geary, A. (2001). Law and aesthetics. Portland, Ore.: Hart.

Goffman, E. (1947). Frame analysis: An essay on the organization of experience. Boston, Ma.: Northeastern University Press.

Gotell, L. (2001). Colonizaiton through disclosure: Confidential records, sexual assault complainants and Canadian law. Social \& legal studies, 10(3), 315-346.

Gotell, L. (2009). Rethinking affirmative consent in Canadian sexual assault law: Neoliberal sexual subjects and risky women. Akron law review, 41, 865-898.

Gotell, L. (2012). Governing heterosexuality through specific consent: Interrogating the governmental effects of R.v J.A.. Canadian journal of women and the law, 24(2), 358-388.

Irigaray, L. (1994). To be two. Translated by Monique M. Rhodes \& Marco F. CocitoMonoc. New York, N.Y.: Routledge.

Kant, I. (1951). Critique of judgement. USA: Hafner. 
IMAGINING LAW

Khan, U. (2017). Fetishizing music as rape culture. Studies in gender and sexuality, 18(1), 19-30.

Laracomb, W. (2002). The 'ideal' victim v. successful rape complainants: Now what you might expect. Feminist legal studies, 10, 131-148.

Łoś, M. (1994). The struggle to redefine rape in the early 1980s. In Julian V. Roberts \& Renate M. Mohr (Eds.) Confronting sexual assault: A decade of legal and social change (pp. 20-56). Toronto, ON.: University of Toronto Press.

Mulla, S. (2014). The violence of care: Rape victims, forensic nurses, and sexual assault intervention. New York, N.Y.: New York University Press.

Nietzche, F., (2006). Thus spoke Zarathustra: A book for all and none. Translated by Adrian Del Caro. Cambridge University Press: Cambridge.

Pavis, P. (1998). Dictionary of the theatre: Terms, concepts, and analysis. Translated by Christine Shantz. Toronto, ON.: University of Toronto Press.

Rozik, E. (2008). Generating theatre meaning: A theory and methodology of performance analysis. Brighton: Sussex Academic Press.

Sheehy, E. (2014). Defending battered women on trial. Vancouver, B.C.: University of British Colombia Press.

Smart, C. (1989). Feminist and the power of law. New York, N.Y.: Routledge.

States, B. O. (1987). Great reckonings in little rooms: On the phenomenology of theatre. Los Angeles, Ca: University of California Press.

Van Marle, K. (2007). Law’s time, particularity and slowness. In Wessel Le Roux (Ed.) Law, memory, and the legacy of apartheid: Ten years after AZAPO v president of South Africa (pp. 11-32). Cape Town: ABC. 
White, J.B. (1972). The legal imagination. Chicago, Il.: Chicago.

\section{Plays}

Ruano, J. (2016). The Ghomeshi effect. Print.

Called to account. (2007). Tricycle theatre.

Guantanamo: Honor bound to defend freedom. (2004). Tricycle theatre.

Half the picture. (1994). Tricycle theatre.

My name is Rachel Corrie. (2006). Tricycle theatre.

Nuremburg. (1996). Tricycle theatre.

Srebrenica. (1996). Tricycle theatre.

The colour of justice. (1999). Tricycle theatre.

\section{Internet Sources}

Boesveld, S. (2017). The Jian Ghomeshi effect: Scandal quickly opening conversation about sexual assault in Canada. National post. Retrieved from: http://nationalpost.com/news/canada/hian-ghomeshi-scandal-quickly-openingconversation-about-sexual-assault-but-as-a-possible-cost.

CBC News. (2016). Jian Ghomeshi trial's not guilty decision triggers outrage, march to police headquarters. $C B C$. Retrieved from:

http.www.cbc.ca/news/canada/toronto/jian-ghomeshi-judge-ruling-1.3504250.

Ciccone, C. (2013). It happened to me: I accidentally went on a date with a presumed-gay Canadian c-list celebrity who creepily proved he isn't gay. XOJane. Retrieved from: https://www.xojane.com/it-happened-to-me/non-date. 
IMAGINING LAW

Coorsh, K. (2016). Protests outside Toronto courthouse following Ghomeshi acquittal. CTV. Retrieved from: http://www.ctvnews.ca/canada/protests-outside-torontocourthouse-following-ghomeshi-acquittal-1.2831313.

Donovan, K., \& Brown, J. (2014). Jian Ghomeshi: 8 women accuse former CBC host of violence, sexual abuse or harassment. Toronto star. Retrieved from: https://www.thestar.com/news/gta/2014/10/29/jian_ghomeshi_8_women_accuse_ former_cbc_host_of_violence_sexual_abuse_or_harassment.html.

Ghomeshi, J. (2014). [Facebook]. As cited by Star Staff. Jian Ghomeshi's full Facebook post: A campaign of false allegations at fault. Retrieved from: https://www.thestar.com/news/gta/2014/10/27/jian_ghomeshis_full_facebook_pos t_a_campaign_of_false_allegations_at_fault.html.

Hasham, A. (2016). Why the Jian Ghomeshi trial may change nothing for sexual assault survivors. Toronto star. Retrieved from: https:/www.thestar.com/news/gta/2016/01/30/why-the-jian-ghomeshi-trial-maychange-nothing-for-sexual-assault-survivors.html.

Kingston, A. (2014). Why the Jian Ghomeshi story has changed everything. Maclean's. Retrieved from: http://www.macleans.ca/culture/this-changes-everything-2/.

Kirsch, J. (2016). How the Jian Ghomeshi trial is affecting my dating life. Toronto star. Retrieved from: https://www.thestar.com/life/2016/03/01/how-the-jian-ghomeshitrial-is-affecting-my-dating-life.html. 
IMAGINING LAW

Khomami, N. (2017). \#MeToo: How a hashtag became a rallying cry against sexual violence. The guardian. Retrieved from:

https:/www.theguardian.com/world/2017/oct/20/women-worldwide-use-hashtagmetoo-against-sexual-harassment.

Loriggio, P. (2016). Jian Ghomeshi trial highlights need for deep legal reform: lawyer.

$C T V$. Retrieved from: http://www.ctvnews.ca/canada/jian-ghomeshi-s-trialhighlights-need-for-deep-legal-reform-lawyer-1.2773667

Macdonald, N. (2016). Jian Ghomeshi trial: When \#believethevictims meets \#dueprocess.

$C B C$. Retrieved from: http://www.cbc.ca/news/canada/due-process-neilmacdonald-1.3446739.

MacMillan, J. (2014). Jian Ghomeshi allegation tracker: A timeline of the harassment and assault accusations. Huffington post Canada. Retrieved from:

http://www.huffingtonpost.ca/2014/11/13/jian-ghomeshi-tips-allegationtracker_n_6136136.html.

Psimenatos, A. (2016, November 7). Courage: Debunking myths and opening a dialogue about sexual violence [Blog post]. Retrieved from:

https://theghomeshieffect.com/2016/11/07/courage-debunking-myths-and-openinga-dialogue-about-sexual-violence/.

Ruprecht, A. (2017) The Ghomeshi effect: Sexual assault results in something being broken! A cathartic encounter at the Gladstone Theatre [Blog post]. Retrieved from: http://capitalcriticscircle.com/the-ghomeshi-effect-sexual-assault-results-insomething-being-broken-a-cathartic-encounter-at-the-gladstone-theatre/. 
IMAGINING LAW

Ryan, D. \& Robinson, M. (2016) The rise and fall of the Ghomeshi effect. Vancouver sun. Retrieved from:

http://www.vancouversun.com/news/rise+fall+ghomeshi+effect/11716879/story.ht $\mathrm{ml}$.

tgemarketing. (2016). The Ghomeshi Effect partners with OCTEVAW to raise awareness about sexual assault [Blog post]. Retrieved from:

https://theghomeshieffect.com/2016/12/14/the-ghomeshi-effect-partners-withoctevaw-to-raise-awareness-about-sexual-assault/.

Wynne-Jones, L. (2014). Ghomeshi gate proves why every man should be a feminist. Huffington post. Retrieved from: http://www.huffingtonpost.ca/lewiswynnejones/jian-ghomeshi-feminism_b_6117330.html.

Young, C. \& The Canadian Press. (2016). Ghomeshi acquitted: Read the verdict and catch up on what you missed. The globe and mail. Retrieved from: https://www.theglobeandmail.com/news/national/jian-ghomeshi/article28476713/.

\section{Legal Decisions}

R. v Ewanchuk, 1 SCR 330. (1999).

R. v Ghomeshi, ONCJ 155. (2016).

R. v J.A., ONCJ 195. (2008).

R. v J.A., ONCA 226. (2010).

R. v J.A., SCC 28. (2011).

R. v Mills. 3 SCR 668. (1999).

R. v Seaboyer. 2 SCR 577. (1991). 